\title{
Estimation of Fracture Properties for a Horizontal Well with Multiple Hydraulic Fractures in Gas Shale
}

Ayodeji L Aboaba

West Virginia University

Follow this and additional works at: https://researchrepository.wvu.edu/etd

\section{Recommended Citation}

Aboaba, Ayodeji L, "Estimation of Fracture Properties for a Horizontal Well with Multiple Hydraulic Fractures in Gas Shale" (2010). Graduate Theses, Dissertations, and Problem Reports. 2166.

https://researchrepository.wvu.edu/etd/2166

This Thesis is protected by copyright and/or related rights. It has been brought to you by the The Research Repository @ WVU with permission from the rights-holder(s). You are free to use this Thesis in any way that is permitted by the copyright and related rights legislation that applies to your use. For other uses you must obtain permission from the rights-holder(s) directly, unless additional rights are indicated by a Creative Commons license in the record and/ or on the work itself. This Thesis has been accepted for inclusion in WVU Graduate Theses, Dissertations, and Problem Reports collection by an authorized administrator of The Research Repository @ WVU. For more information, please contact researchrepository@mail.wvu.edu. 


\title{
Estimation of Fracture Properties for a Horizontal Well with Multiple Hydraulic Fractures in Gas Shale
}

\author{
Ayodeji L. Aboaba \\ Thesis Submitted to the \\ College of Engineering and Mineral Resources at \\ West Virginia University \\ In partial fulfillment of the requirements for the degree of
}

\author{
Master of Science \\ In \\ Petroleum and Natural Gas Engineering \\ Dr. Yueming Cheng, PhD., Chair \\ Dr. Khashayar Aminian, PhD. \\ Samuel Ameri, M.S.
Department of Petroleum and Natural Gas Engineering
Morgantown, West Virginia \\ 2010
}

Keywords: Multiple hydraulic fractures, linear flow, Pressure transient, horizontal well, Gas shale. 


\title{
ABSTRACT \\ ESTIMATION OF FRACTURE PROPERTIES FOR A HORIZONTAL WELL WITH MULTIPLE HYDRAULIC FRACTURES IN GAS SHALE
}

\begin{abstract}
Ayodeji L. Aboaba
This research work presents a new method for estimating fracture properties for a horizontal well with multiple hydraulic fractures in shale gas reservoirs. This method utilizes the production data obtained during the linear flow period to provide reliable estimates of both fracture half-length and formation permeability.

The new method provides an excellent alternative to the conventional pressure transient analysis methods. It requires neither the existence of the elliptical flow nor the pseudoradial flow periods and thus reduces the impractical long times required for well testing in horizontal wells drilled in shale gas reservoirs. The conventional pressure transient analysis methods require an independent estimate of formation permeability from the pseudo-radial flow period in other to estimate fracture half-length and fracture conductivity from linear and bilinear flow periods respectively.
\end{abstract}

A readily available noisy production data can be easily analyzed for fracture property estimates using the new method by coupling with a stable deconvolution technology which converts variable production-rate and pressure measurements into an equivalent constant-rate pressure drawdown test. The required inputs to utilize the proposed methodology are production data and basic reservoir properties such as formation thickness, formation temperature, porosity, fluid compressibility and viscosity.

Because of the relative simplicity of this method, it does not require special expertise to use. This study presents synthetic cases to illustrate the proposed method and demonstrate its' validity and applicability. 


\section{ACKNOWLEDGEMENTS}

I express my sincere gratitude to Dr. Yueming Cheng, my research advisor and academic sponsor, for her constant financial and academic support throughout the course of this research work and my graduate study at West Virginia University. Her professionalism and knowledge of the subject of research is splendid. Her financial support, professional assistance and advice are greatly appreciated.

I would also like to thank the other members of my research committee. I strongly appreciate the constant support and advice from Dr. Sam Ameri, Department Chair, Petroleum and Natural Gas Engineering department. He has been a father and friend throughout my study at the university. I greatly appreciate the continuous support from Dr. Khashayar Aminian, for his wisdom and excellent communications skills as an educator. He has greatly impacted my academic life. It is my pleasure and honor to have him on my committee.

I would like to thank everyone in the Department of Petroleum and Natural Gas Engineering, especially Ms. Beverly Matheny for her friendly ambience.

My sincere appreciation also goes to my parents for their unconditional love, financial and moral supports, prayers and advice throughout my endeavors in life. I cannot thank you enough. I also thank my siblings, Doyinsola, Abiodun and Abiola Aboaba, for their love and understanding. And to my wife, Bola Aboaba, I thank you for being there always. 


\section{TABLE OF CONTENTS}

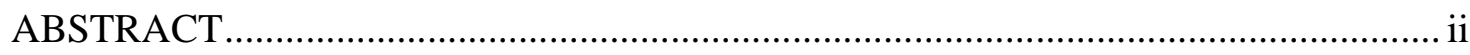

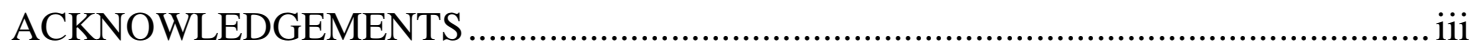

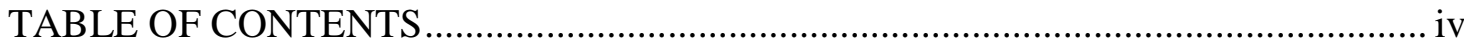

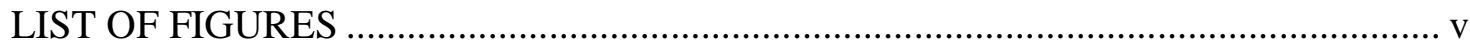

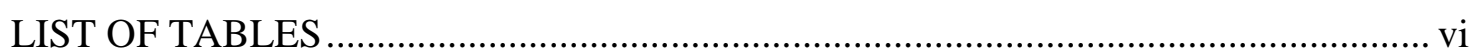

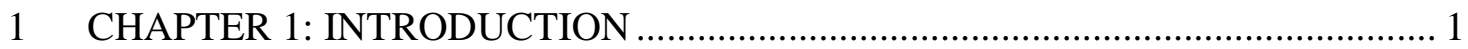

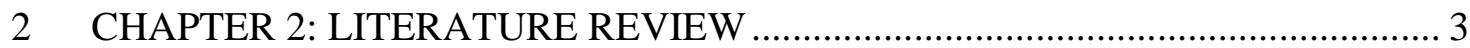

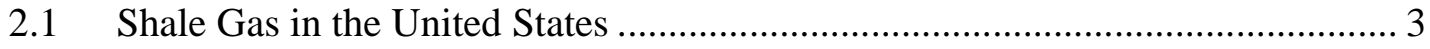

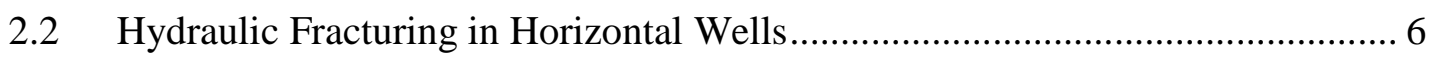

2.3 Pressure Transient Behavior of Fractured Horizontal Wells ............................... 7

2.4 Conventional Pressure Transient Analysis Techniques: .................................. 10

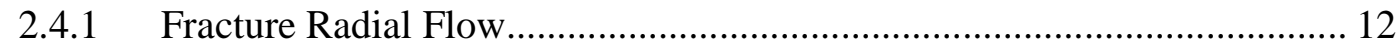

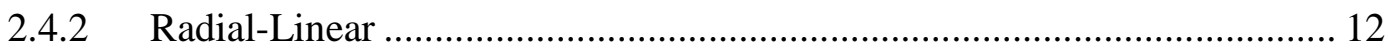

2.4.3 Bilinear Flow ................................................................................... 13

2.4.4 Formation Linear Flow …....................................................................... 14

2.4.5 Pseudo-Radial Flow .............................................................................. 16

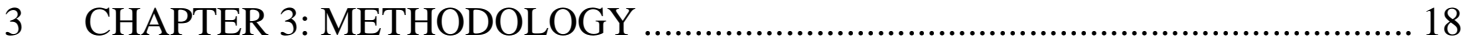

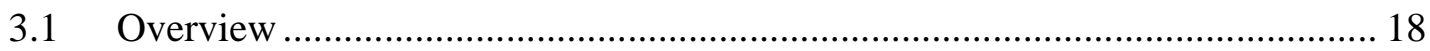

3.2 Reservoir Model of Study ....................................................................... 19

3.3 Formation Linear Flow Solution ................................................................. 19

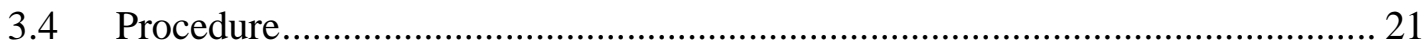

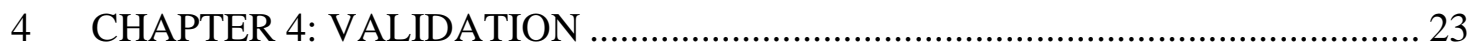

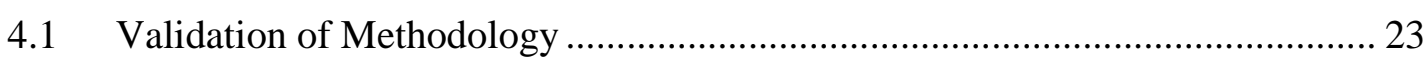

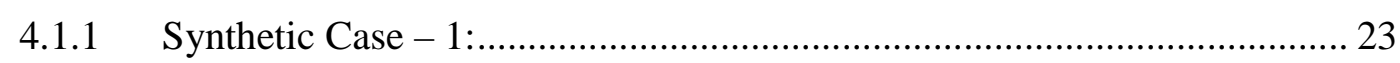

4.1.2 Application of developed method to Synthetic Case - 1.......................... 25

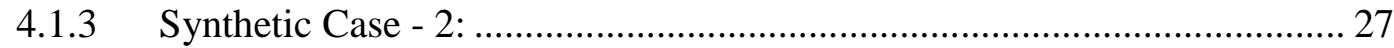

4.1.4 Application of developed method to Synthetic Case - 2 2......................... 29

4.2 Results Summary (Synthetic Case - 1) ............................................................ 31

4.3 Results Summary (Synthetic Case - 2) ........................................................ 31

5 CHAPTER 5: CONCLUSIONS \& RECOMMENDATIONS ................................. 33

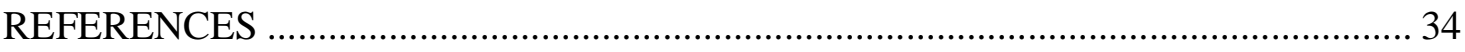

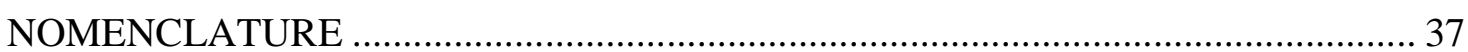




\section{LIST OF FIGURES}

Figure 1- Gas Shale Basins in the United States with Estimated Gas Reserves................ 4

Figure 2 - Potential Flow Regimes for Fractured Horizontal Wells ................................. 11

Figure 3 - Effect of Fracture Aspect Ratio on the Potential Early Time Flow Regimes of Horizontal Wells with a Transverse Rectangular Fracture . ........................... 11

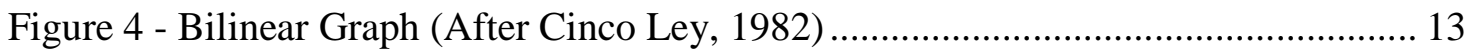

Figure 5 - Linear Flow Graph (After Cinco Ley, 1982) ............................................. 15

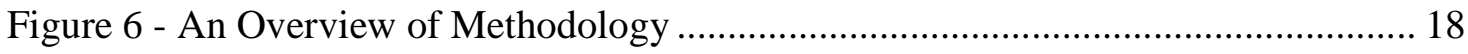

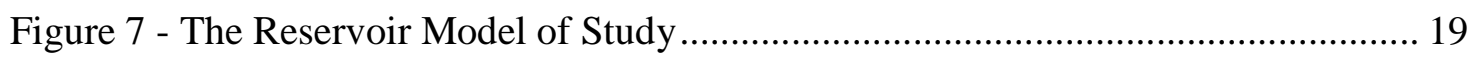

Figure 8 - The well, fractures and reservoir model for synthetic case 1 ......................... 24

Figure 9 - Production Performance Curve for Synthetic Case-1 ................................... 24

Figure 10 - Cumulative Gas Production vs. Time for Synthetic Data Case-1 ................. 25

Figure 11 - Diagnostic Plot for Synthetic Case - 1 ........................................................... 26

Figure 12 - Specific Linear Plot of Pseudo-Pressure Drawdown vs. $\mathrm{t}^{1 / 2}$ for

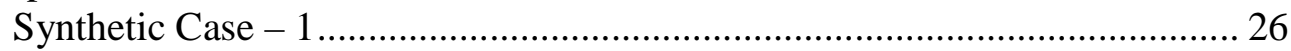

Figure 13 - The well, fractures and reservoir model for synthetic case 2 ...................... 28

Figure 14 - Production Performance Curve for Synthetic Case-2 .................................. 28

Figure 15 - Cumulative Gas Production vs. Time for Synthetic Case-2 ........................ 29

Figure 16 - Diagnostic Plot for Synthetic Case -2 ................................................. 30

Figure 17 - Specific Linear Plot of Pseudo-Pressure Drawdown vs. $t^{1 / 2}$ for Synthetic Case - 2 


\section{LIST OF TABLES}

Table 1 - Comparison of Data for the Gas Shale in the United States............................... 5

Table 2-Reservoir Simulation Model Input Parameters (Synthetic Case - 1) .................. 23

Table 3 - Reservoir Simulation Model Input Parameters (Synthetic Case - 2) ................ 27

Table 4 - Comparison Between the True Values and the Estimated Values

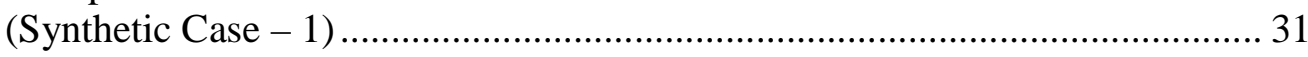

Table 5 - Comparison Between the True Values and the estimated values (Synthetic Case - 2) 


\section{CHAPTER 1: INTRODUCTION}

At the core of shale gas development are two key technologies: horizontal drilling and hydraulic fracturing. In very low permeability gas reservoirs such as shale, hydraulic fracturing is the preferred technique to improve productivity. The main idea of hydraulic fracturing is to create a high-permeability flow path which extends far beyond any damage zone around the wellbore and therefore attracts fluid from the undisturbed parts of the reservoir. Horizontal drilling technology has also been another means of increasing drainage area and productivity in low permeability reservoirs.

Pressure transient testing uses the pressure signature of a well during a producing or shutin period as a function of time to identify reservoir characteristics and estimate reservoir parameters. Hydraulic fractures produce a pressure response that is different from unfractured reservoirs and can therefore be used to identify fractures and infer fracture parameters. The well trajectory and low reservoir permeability in formations such as shale make pressure transient test analysis in hydraulically fractured horizontal wells more challenging. Pressure transient testing in shale is characterized by longer transient periods compared with the conventional petroleum reservoirs.

The conventional pressure transient analysis methods require a fore-knowledge of the reservoir permeability to estimate both fracture half-length and fracture conductivity from linear flow and bilinear flow periods respectively. The existence of the elliptical or pseudo-radial flow periods is a pre-requisite to provide an estimate of reservoir permeability. Due to the formation characteristics, it takes a very long time to reach either the elliptical or pseudo-radial flow periods.

This research study presents a unique method of estimating both fracture half-length and matrix permeability using early time production data. The method developed in this study uses two linear flow equations which are generated from the conventional working equations for linear flow in vertical wells. The method involves the use of the conventional diagnostic plot of pressure derivative and change in pseudo-pressure versus time, and the specific linear plot of change in pseudo-pressure versus square root of time. 
An accurate knowledge of the end of linear flow period is a pre-requisite to obtain reliable results using this method.

The results of this research study show that this method provides reliable estimates of both shale matrix permeability and average fracture half-length in horizontal wells with multiple hydraulic fractures in shale gas reservoirs. 


\section{CHAPTER 2: LITERATURE REVIEW}

\subsection{Shale Gas in the United States}

Shale gas is natural gas produced from hydrocarbon rich shale formations. Natural gas plays a key role in meeting U.S. energy demands. Natural gas, coal and oil supply about $85 \%$ of the nation's energy, with natural gas supplying about $22 \%$ of the total (David, 2008). The percent contribution of natural gas to the U.S. energy supply is expected to remain fairly constant for the next 20 years (David, 2008).

The United States has abundant natural resources. The Energy Information Administration estimates that the U.S. has more than 1,744 trillion cubic feet (tcf) of technically recoverable natural gas, including $211 \mathrm{tcf}$ of proved reserves (the discovered, economically recoverable fraction of the original gas-in-place) (API, 2010). Technically recoverable unconventional gas (shale gas, tight sands, and coalbed methane) accounts for $60 \%$ of the onshore recoverable resources (David, 2008). At the U.S production rates for 2007, about $19.3 \mathrm{tcf}$, the current recoverable resource estimate provides enough natural gas to supply the U.S. for the next 90 years (API, 2010).

The lower 48 states have a wide distribution of highly organic shale containing vast resources of natural gas. Already, the fledgling Barnett Shale play in Texas produces 6\% of all natural gas produced in the lower 48 states (David, 2008). Analysts have estimated that by 2011 most new reserves growth (50\% to $60 \%$, or approximately 3 bcf/day) will come from unconventional shale gas reservoirs (David, 2008). According to a study carried out by David (2008), the total recoverable gas resources in four new shale gas plays (the Haynesville, Fayetteville, Marcellus, and Woodford) may be over 550 tcf. Figure 1 shows the approximate locations of gas shale basins in the United States with estimated gas reserves (Daniel Arthur, 2009). 


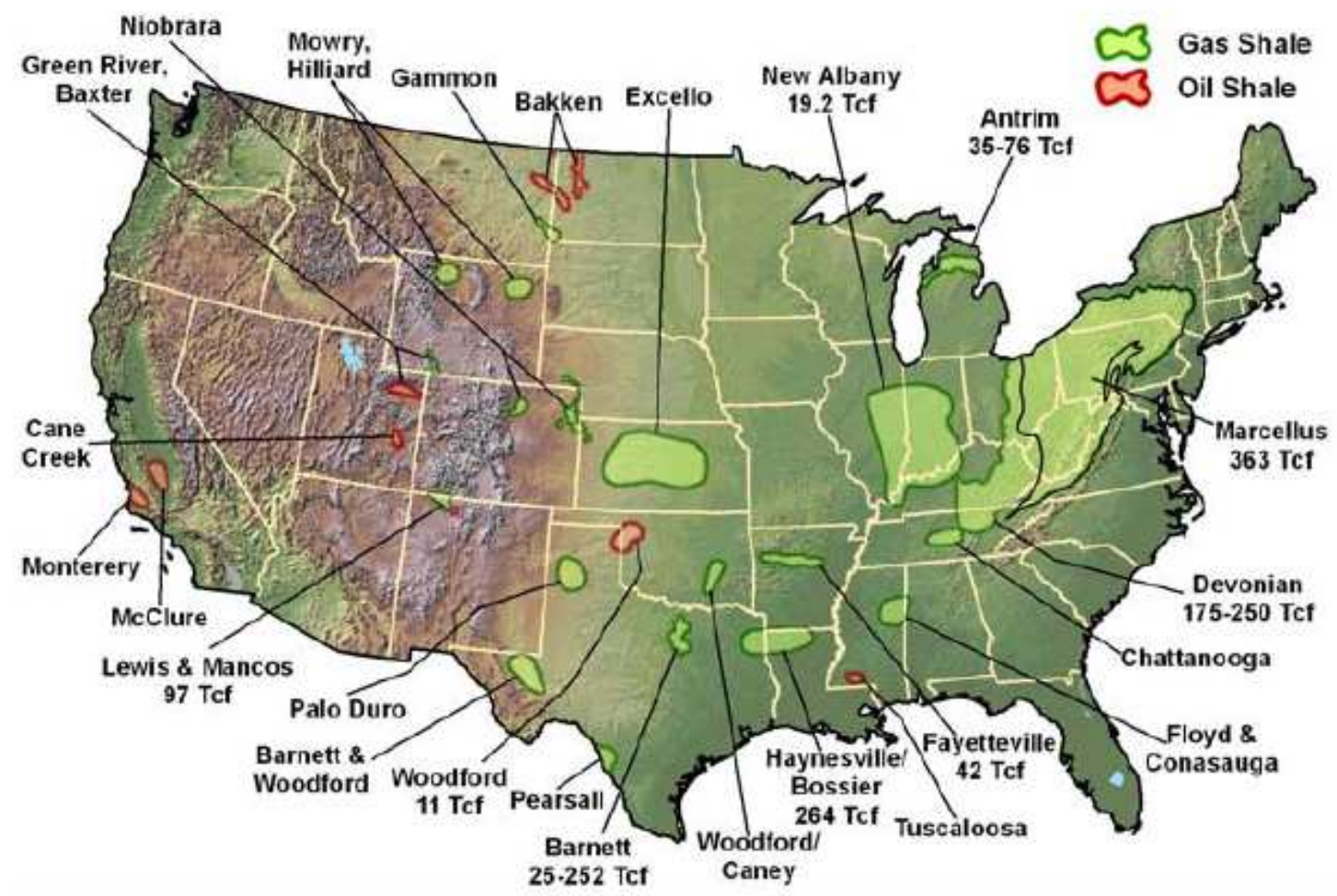

Figure 1- Gas Shale Basins in the United States with Estimated Gas Reserves (After Daniel Arthur, 2009) 
The table below presents a comparison of data for gas shale in the United States.

Table 1 - Comparison of Data for the Gas Shale in the United States (After David, 2008)

\begin{tabular}{|c|c|c|c|c|c|c|c|c|}
\hline $\begin{array}{c}\text { Gas Shale } \\
\text { Basin }\end{array}$ & Barnett & Marcellus & Fayetteville & Haynesville & Woodford & Antrim & $\begin{array}{l}\text { New } \\
\text { Albany }\end{array}$ & Lewis \\
\hline $\begin{array}{l}\text { Estimated } \\
\text { Basin Area, } \\
\text { square miles }\end{array}$ & 5,000 & 95,000 & 9,000 & 9,000 & 11,000 & 12,000 & 43,500 & 10,000 \\
\hline Depth, $\mathrm{ft}$ & $\begin{array}{l}6,500- \\
8,500\end{array}$ & $\begin{array}{l}4,000- \\
8,500\end{array}$ & $\begin{array}{l}1,000- \\
7,000\end{array}$ & $\begin{array}{c}10,500- \\
13,500\end{array}$ & $\begin{array}{l}6,000- \\
11,000\end{array}$ & $\begin{array}{l}600- \\
2,200\end{array}$ & $\begin{array}{l}500- \\
2,000\end{array}$ & $\begin{array}{r}3,000- \\
6,000\end{array}$ \\
\hline $\begin{array}{l}\text { Net Thickness, } \\
\mathrm{ft}\end{array}$ & $\begin{array}{l}100- \\
600\end{array}$ & $50-200$ & $20-200$ & $200-300$ & $120-220$ & $70-12$ & $50-100$ & $200-300$ \\
\hline $\begin{array}{l}\text { Depth to Base } \\
\text { of Treatable } \\
\text { Water, } \mathrm{ft}^{\underline{z}}\end{array}$ & $\sim 1200$ & $\sim 850$ & $\sim 500$ & $\sim 400$ & $\sim 400$ & $\sim 300$ & $\sim 400$ & $\sim 2000$ \\
\hline $\begin{array}{l}\text { Rock Column } \\
\text { Thickness } \\
\text { between Top of } \\
\text { Pay and Bottom } \\
\text { of Treatable } \\
\text { Water }\end{array}$ & $\begin{array}{c}5,300- \\
7,300\end{array}$ & $\begin{array}{c}2,125- \\
7650\end{array}$ & $\begin{array}{l}500- \\
6,500\end{array}$ & $\begin{array}{c}10,100- \\
13,100\end{array}$ & $\begin{array}{l}5,600- \\
10,600\end{array}$ & $\begin{array}{l}300- \\
1,900\end{array}$ & $\begin{array}{l}100- \\
1,600\end{array}$ & $\begin{array}{l}1,000- \\
6,000\end{array}$ \\
\hline $\begin{array}{l}\text { Total Organic } \\
\text { Carbon, \% }\end{array}$ & 4.5 & $3-12$ & $4.0-9.8$ & $0.5-4.0$ & $1-14$ & $1-20$ & $1-25$ & $0.45-2.5$ \\
\hline $\begin{array}{l}\text { Total Porosity, } \\
\%\end{array}$ & $4-5$ & 10 & $2-8$ & $8-9$ & $3-9$ & 9 & $10-14$ & $3.0-5.5$ \\
\hline $\begin{array}{l}\text { Gas Content, } \\
\text { scf/ton }\end{array}$ & $\begin{array}{l}300- \\
350\end{array}$ & $60-100$ & $60-220$ & $100-330$ & $200-300$ & $40-100$ & $40-80$ & $15-45$ \\
\hline $\begin{array}{l}\text { Water } \\
\text { Production, } \\
\text { Barrels } \\
\text { water/day }\end{array}$ & 0 & 0 & 0 & 0 & & $5-500$ & $5-500$ & 0 \\
\hline $\begin{array}{l}\text { Well spacing, } \\
\text { Acres }\end{array}$ & $60-160$ & $40-160$ & $80-160$ & $40-560$ & 640 & $40-160$ & 80 & $80-320$ \\
\hline $\begin{array}{l}\text { Original Gas-In- } \\
\text { Place, Tcf }\end{array}$ & 327 & 1,500 & 52 & 717 & 52 & 76 & 160 & 61.4 \\
\hline Reserves, Tcf & 44 & 262,500 & 41.6 & 251 & 11.4 & 20 & 19.2 & 20 \\
\hline $\begin{array}{l}\text { Est. Gas } \\
\text { Production, } \\
\text { mcf/day/well }\end{array}$ & 338 & 3,100 & 530 & $625-1,800$ & 415 & $\begin{array}{l}125- \\
200\end{array}$ & & $100-200$ \\
\hline \multicolumn{9}{|c|}{$\begin{array}{l}\text { NOTE: Data derived from various sources and research analysis. Information from some basins was unable to be } \\
\text { identified and confirmed at the time of this paper and has been left blank. } \\
\text { \# - for the Depth to base of treatable water data, the data was based on depth data from state oil and gas agencies and } \\
\text { state geological survey data. }\end{array}$} \\
\hline \multicolumn{9}{|c|}{$\begin{array}{l}\text { SOURCE: Hayden \& Pursell, 2005; Halliburton, 2008; Navigant Consulting, 2008; Drilling Contractor, 2000; Boughal, } \\
\text { 2008; Berman, 2008; Haines, 2006; Arkansas Oil and Gas Commission, 2008; Nyahay, Leone, Smith, Martin, \& Jarvie, } \\
\text { 2007; Cardott, 2004; Soeder, 1986; Vulgamore et al, 2007; Petroleum Listing Services, 2008; Jochen, 2006; Sumi, } \\
\text { 2008; Engelder \& Lash, 2008; Williams, 2008; Gas Leases, 2008; US Energy Investor, 2005. }\end{array}$} \\
\hline
\end{tabular}


Shale acts as both the source and the reservoir for the natural gas. A typical shale rock has limited permeability horizontally and extremely minimal permeability vertically; typically unfractured shale has permeability in the micro to nano-darcy range (Brian, 2007). The low natural permeability of shale has been a limiting factor to the production of gas shale resources (Ameri \& Yost II, 1985). Older shale gas wells were vertical while more recent wells are primarily horizontal and need artificial stimulation, like hydraulic fracturing, to produce. The most significant trend in U.S natural gas production is the rapid rise in production from shale formations (API, 2010). In large measure, this is attributable to significant advances in the use of horizontal drilling and well stimulation technologies and refinement in the cost effectiveness of these technologies. Hydraulic fracturing is the most significant of these.

\subsection{Hydraulic Fracturing in Horizontal Wells}

Hydraulic fracturing has been shown to be an effective way of significantly enhancing the performance of horizontal wells. Multiple fracturing of horizontal wells has been shown to be both a viable and successful approach. In a tight naturally fractured gas reservoir, the productivity of a multi-fractured horizontal well is shown to be several times greater than that achieved by a stimulated vertical well (Yost A.B., 1989). Yost et al. presented a practical view of the fracturing treatment of a horizontal well in a naturally fractured reservoir. They reported improvement ratios six days after fracturing ranging from 4 to 35 in different zones along the horizontal wellbore. Multiple hydraulic fracturing is especially beneficial in low permeability formations and where low vertical permeability reduces the effectiveness of horizontal wells. Horne et al. have investigated the conditions under which multiple fractures provide significant improvement over a single fracture (Horne., 1995). The study showed that the effectiveness of creating multiple fractures along a horizontal well depends on the relative lengths of the well and the fractures as well as the time at which the comparison is economically significant.

Two types of hydraulic fractures are possible with horizontal wells (Soliman M.Y., 1990); if the axis of the well is normal to the minimum horizontal stress direction then a single large fracture is formed along the axis of the well. Fractures transverse to the wellbore axis will be created when the well is parallel to the minimum horizontal stress. More complicated fracture geometries will result if the wellbore axis is not normal to 
either principal horizontal stress directions. Techniques used to hydraulically fracture horizontal wells completed in shale reservoirs often require larger volumes of fracturing fluid than might be common for conventional, vertical well stimulations.

\subsection{Pressure Transient Behavior of Fractured Horizontal Wells}

The effect of hydraulic fractures on the pressure transient behavior of vertical wells has been documented extensively in the petroleum literature. Gringarten et al presented type curve and basic equations for uniform flux and infinite conductivity fractures intercepted by a vertical wellbore, with the infinite conductivity assumption only valid for highly conductive fractures (Gringarten 1975). Transient flow within fractures was not included in these models. For both models, the initial flow period is the formation linear flow period. During the pseudo-radial flow period a fractured well behaves like an unfractured well with an augmented effective wellbore radius. From the analytical solutions the effective wellbore radius can be shown to be half of the fracture half length for infinite conductivity and uniform flux fractures.

Cinco-Ley et al. (Cinco-Ley 1978) and Cinco-Ley and Samaniego (Cinco-Ley 1981) presented general solutions for the pressure transient behavior of a vertical well intersected by a finite conductivity vertical fracture. The method applied by Cinco-Ley et al. is semi-analytical; utilizing Green's and source functions. They showed that for dimensionless fracture conductivities equal to or greater than 300 , the finite-conductivity solutions are for all practical purposes identical to the infinite conductivity solution. The uniform flux solution behaves like the infinite conductivity solution at early times, while at intermediate times it follows a variable fracture conductivity solution. For late times it follows a dimensionless fracture conductivity solution of 4.4. Cinco-Ley et al. (1981) also introduced the concepts of fracture linear flow and bilinear flow. During the fracture linear flow period, most of the fluid entering the wellbore comes from the expansion of the system within the fracture and the flow is essentially linear. The bilinear flow period occurs whenever most of the fluid entering the wellbore comes from the formation and fracture tip effects has not yet affected the pressure behavior. The period is called bilinear because of simultaneous transient linear flow in the fracture and in the formation. CincoLey et al. also presented type curves and straight-line analyses methods to determine fracture parameters. For finite conductivity fractures, the effective wellbore radius is 
related to the fracture conductivity. Prats introduced a correlation between effective wellbore radius and dimensionless fracture conductivity (Prats 1961).

Schulte evaluated the effect of limited flow entry in vertical wells with a finiteconductivity fracture (Schulte, 1986). He showed that the early transient data can exhibit a radial-linear (or linear-radial) flow period comparable to the bilinear flow regime for a fully penetrating fractured vertical well. Type curves were generated using both a numerical simulator and analytically derived Laplace transformed solutions for the radiallinear period, or actually semi-radial-linear for the cases considered. The storativity of the fracture was ignored. For not-too-small values of time, the dimensionless pressure was expressed analytically. An expression for the expected skin value due to limited flow entry was also presented. It was shown that the productivity of a fractured well may be significantly reduced if the inflow interval is much smaller than the fracture height.

Schulte's equations also describe the situation with a horizontal well penetrating a vertical fracture during the radial-linear flow period. Soliman et al. also presented similar equations for a horizontal well intercepted by a transverse finite-conductivity fracture with storativity of the fracture included. They also evaluated the effect of a step change in fracture conductivity. It was demonstrated that the fracture performance depends on both the magnitude and the distribution of conductivity and does not depend solely on the average of the fracture conductivity, with low fracture conductivity near the wellbore naturally reducing the productivity.

Davlau et al. proposed that there are two identifiable flow regimes during transient flow, early-time radial and late-time pseudo-radial flow (Davlau, 1985). Davlau et al. presented the analytical solutions for pressure during these two flow regimes and the corresponding durations of the regimes for transient-test analysis. They were the first to consider wellbore storage effects in horizontal wells by coupling their model with the Cinco-Ley and Samaniego (Cinco-ley, 1977) numerical model. Based on the relative magnitude of wellbore length and reservoir thickness, Clonts and Ramey (Clonts, 1986) considered two types of transient pressure behavior in an infinite reservoir, an initial radial flow followed by a transition to a pseudo-radial flow for a short drainhole and a rapidly ending initial radial flow followed by the pressure behavior of a uniform flux vertical fracture for a long drainhole. Like Davlau et al. (Davlau, 1985), they presented 
analytical equations for short-time radial and long-time pseudo-radial flow and time criteria. Their solution is a solution for the uniform-flux condition.

Ozkan presented an extensive library of solutions in terms of the Laplace transform variable; he considered a wide variety of wellbore configurations, different bounded systems, and homogeneous or double-porosity reservoirs (Ozkan, 1988). Chen and Raghavan used Ozkan's solutions in studying a multiply fractured horizontal well in infinite systems, they accounted for the interference between fractures by the superposition of influence functions, their work only dealt with 2D fractures in isotropic system (Raghavan, 1997). As discussed by Chen (1997), and Raghavan and Chen (1997), at long times, a multiply fractured horizontal well behaves like a single fracture between the two outermost fractures along the horizontal well. Aziz et al. extended the work done by Chen and Raghavan by building new analytical solutions for 3D fractures based on published 2D solutions (Aziz, 1999). Larsen and Hegre presented general solutions for fractured horizontal wells based on numerical integration of Laplace-transformed pointsource solutions for unbounded reservoirs in three dimensions (Larsen, 1991). Laplacetransformed solutions were presented for circular and rectangular uniform flux fractures, and these were used to obtain finite conductivity solutions by a scheme similar to that used by Cinco-Ley et al. for vertically fractured wells. To generate upper and lower boundaries of the formation, and to add fractures along the wellbore, straightforward image-well techniques were used. It was also shown that solutions for double-porosity and layered reservoirs with transient inter-porosity flow can be applied for short flowing times (Serra, 1983). Larsen et al extended the study made by Larsen and Hegre (1991) by identifying the flow periods exhibited by single and multi-fractured horizontal wells with transverse or longitudinal fractures. They presented equations to analyze the different flow periods using the log-log and straight line analyses (Larsen, 1994).

Medeiros et al. have shown that the flow regimes for a horizontal well with transverse and longitudinal hydraulic fractures differ only at early and intermediate times (Medeiros, 2007). Transverse fractures display radial flow convergence at early times while longitudinal fractures exhibit a linear flow regime. Longitudinal fractures display an intermediate-time reservoir linear flow. For transverse fractures, intermediate-time linear flow may or may not develop depending on the fracture configurations, conductivities, 
and reservoir properties. After intermediate times, horizontal wells with both transverse and longitudinal fractures show the same flow regimes. Their results indicate that hydraulically fracturing horizontal wells in naturally fractured reservoirs may not contribute to productivity significantly unless very large fracture conductivities are achieved. Tiab et al. developed a set of type curves that include bilinear, linear, radial, biradial, and pseudo-radial flow regimes (Tiab, 2004). Equations were developed describing the unique characteristics of the five flow regimes to calculate the number of active fractures, equivalent fracture conductivity and total system conductivity, equivalent half-fracture length, reservoir directional permeabilities and equivalent skin. The cases of uniform flux, infinite conductivity and finite conductivity models are considered.

Ozkan et al., (2009) presented an analytical trilinear flow solution which incorporates the fundamental petrophysical characteristics of unconventional reservoirs; including the intrinsic matrix and natural fracture properties, to simulate the pressure transient and production behavior of fractured horizontal wells in tight formations. The trilinear flow model is based on the premise that the productive lives of fractured horizontal wells in tight formations are dominated by linear flow regimes. One dimensional linear flow, similar to flow in vertical-well fractures, is assumed in the hydraulic fractures because wellbore storage masks the very early time (radial) flow convergence towards the well within the hydraulic fractures (Soliman et al., 1990, Mukherjee et al., 1991, and Larsen and Hegre., 1991, 1994). Ozkan et al (2006, 2009) accounted for the impact of radial flow convergence by applying a flow choking skin and incorporating the wellbore storage effect into the trilinear flow model by convolution.

\subsection{Conventional Pressure Transient Analysis Techniques:}

In theory, up to five flow regimes could appear during horizontal-well transient flow. However, the existence of these flow regimes is closely associated with the dimensions of the reservoir drainage volume, wellbore length, and permeability anisotropy, etc. Hence, it is common that some of flow regimes are not present. The following shows the possible flow regimes for fractured horizontal wells (Ozkan, 2006). 


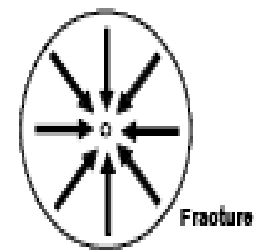

1. Fracture Radlal Flow

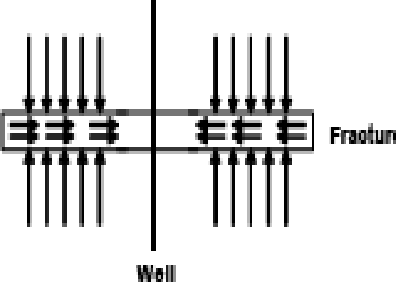

2. Radla|-Inear or Billnear Flow

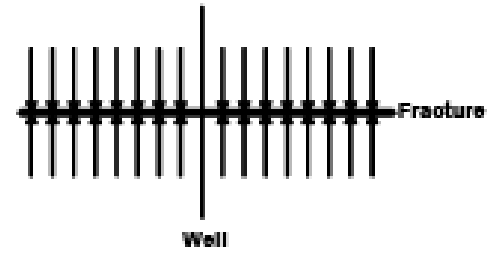

3. Formation LInear Flow

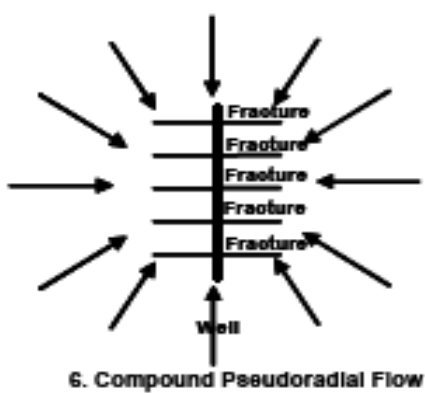

6. Compound Pseudoradlal Flow

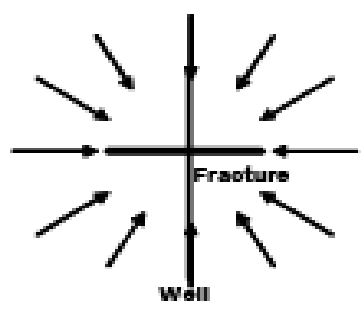

4. Preudo-Radlal Flow

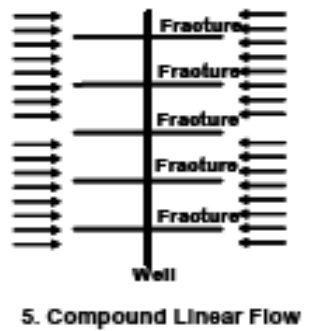

Figure 2 - Potential Flow Regimes for Fractured Horizontal Wells (After Ozkan et al., 2006)

Ozkan et al. presented some results to demonstrate the existence of flow regimes as a function of fracture properties and geometries (Ozkan, 2006). Fig 3 shows the effect of the aspect ratio on the potential early-time flow regimes of horizontal wells with a transverse, rectangular fracture (Ozkan, 2006).

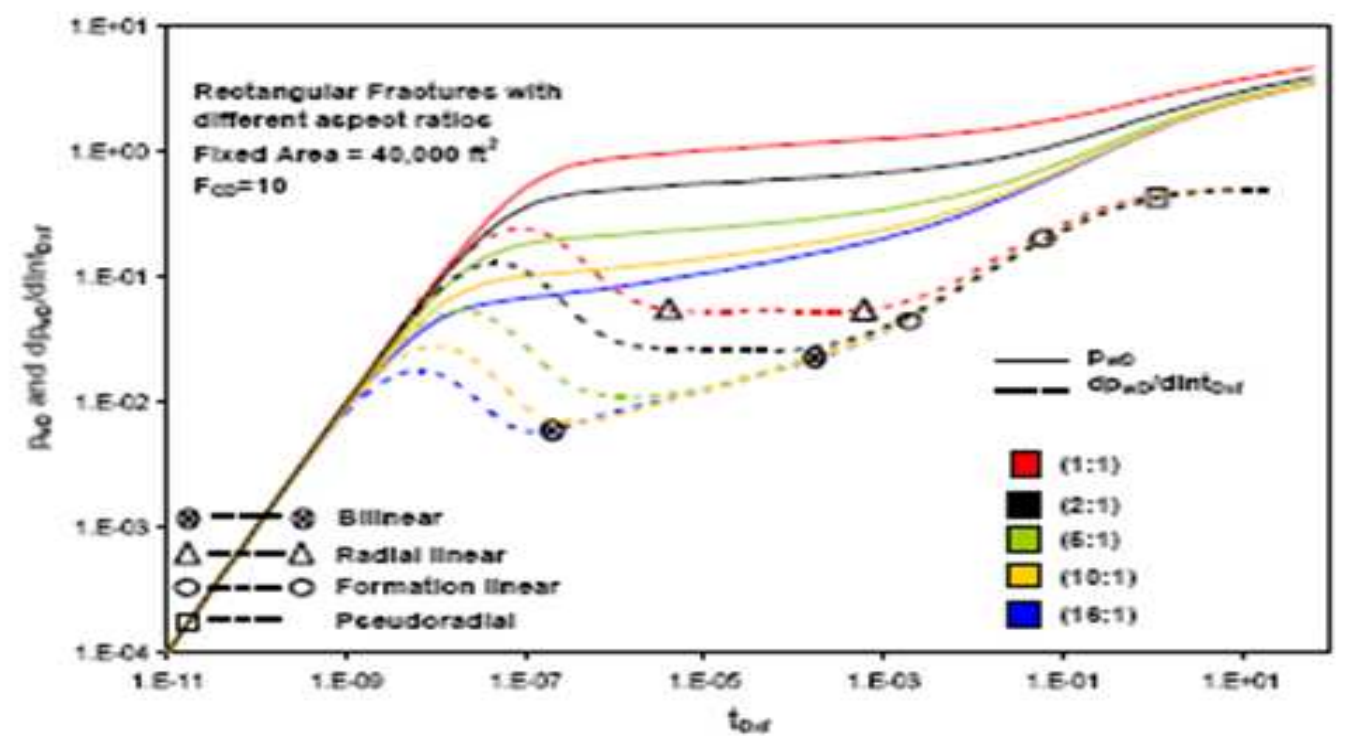

Figure 3 - Effect of Fracture Aspect Ratio on the Potential Early Time Flow Regimes of Horizontal Wells with a Transverse Rectangular Fracture (After Ozkan, 2006). 
Horizontal-well transient test analysis mainly includes conventional analysis techniques relying on approximate analytical models, and nonlinear regression techniques relying on semi-analytical models. In conventional analysis techniques, each flow regime is described by an analytical expression, which indicates certain kind of linear relationship between pressure and pressure derivative versus time, such as semi-log linear or square root linear relations. These expressions are approximations of transient pressure responses, derived from the original solution of the boundary value problem. The time duration corresponding to each expression (or flow regime) is estimated to help identify the flow regimes. The conventional interpretation methods for horizontal well test data are similar to those for vertical wells (Lichtenberger, 1994).

\subsubsection{Fracture Radial Flow}

The fracture radial flow period is usually short lived. For practical purposes, this flow period is usually not analyzed because it is usually masked by wellbore storage (Soliman et al., 1990, Mukherjee et al., 1991, and Larsen and Hegre., 1991, 1994).

\subsubsection{Radial-Linear}

Larsen and Hegre (1994) showed that the radial-linear flow solution for a fully penetrating fracture intercepted by a horizontal well at its center is given by

$$
p_{w D}=\frac{h_{D}}{4 F_{C D}}\left(\ln t_{D x f}+\ln \frac{F_{C D}^{2}}{4 r_{w D}^{4}}+1.5209\right)
$$

In dimensional form, equation 2.10 becomes

$$
\Delta p_{w f}=\frac{162.6 q B \mu}{2 k_{f} w_{f}}\left[\log \left(\frac{2.64 \times 10^{-4} k t}{\phi \mu c_{t} r_{w}^{2}}\right)+\log \left(\frac{k_{f} w_{f}}{2 k r_{w}}\right)^{2}+0.6604\right]
$$

Equation 2.11 indicates that if radial-linear flow exists, then a semi-log plot of pressure versus logarithm of time yields a straight line with slope $m_{r l}$ given by

$$
m_{r l}=\frac{162.6}{2} \frac{q B \mu}{k_{f} w_{f}}
$$

Thus, the fracture conductivity, $k_{f} w_{f}$, can be calculated directly from equation (2.12) and it is not necessary to know the formation height or reservoir permeability. 


\subsubsection{Bilinear Flow}

This flow period occurs in finite conductivity fractures as fluid in the surrounding formation flows linearly into the fracture and before fracture-tip effects begin to influence well behavior. During the bilinear flow period, $P_{w f}$ is a linear function of $t^{1 / 4}$ on cartesian co-ordinate paper (Figure 4).

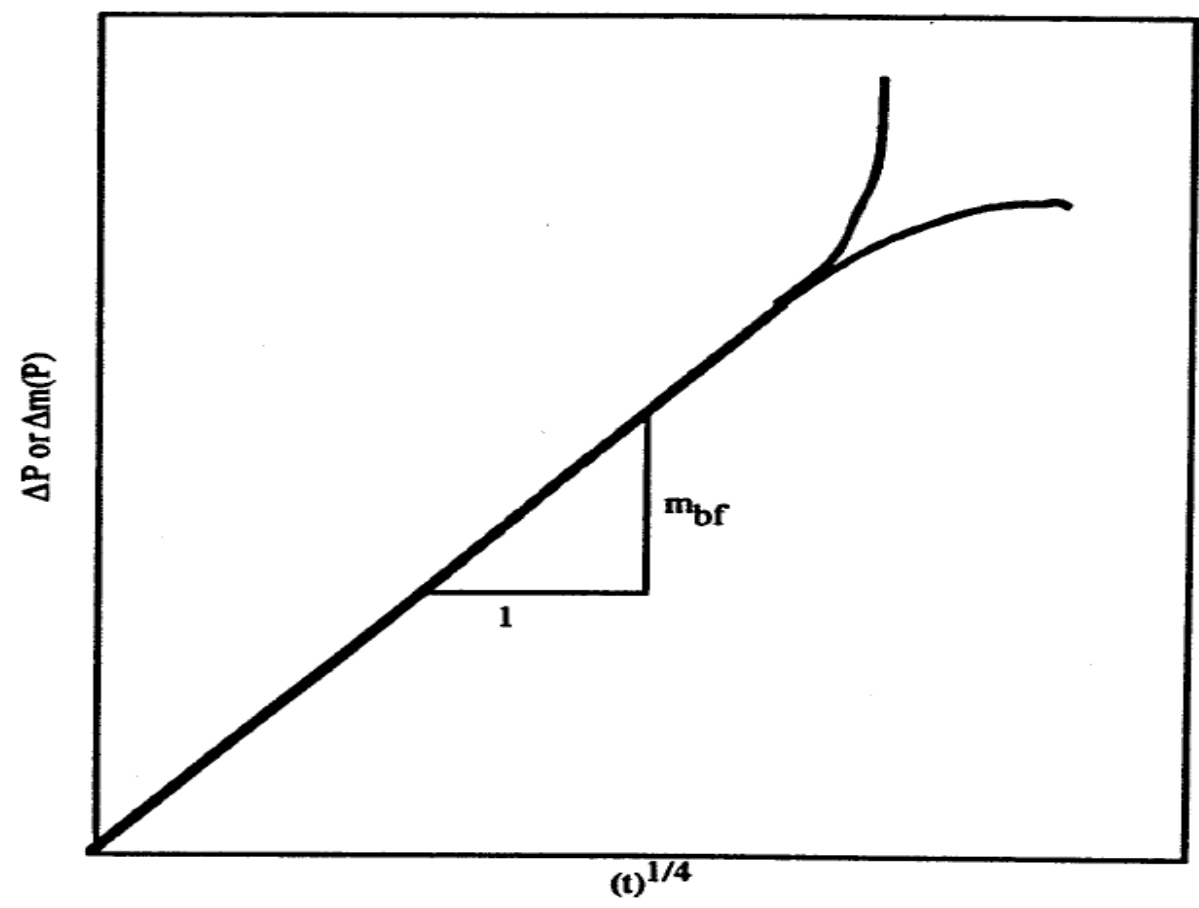

Figure 4 - Bilinear Graph (After Cinco Ley, 1982)

A log-log plot of $\left(p_{i}-p_{w f}\right)$ as a function of time exhibits a slope of one-quarter during this time period. The dimensionless pressure response during the pseudo-bilinear flow period is given by Ozkan (2006) as

$P_{D}=\frac{2.45}{\sqrt{F_{C D}}} \sqrt[4]{t D x f}+S_{p}\left(\mathrm{~F}_{\mathrm{CD}}, \mathrm{h}_{\mathrm{D}}\right)$

Where $S_{p}$ is the pseudo-skin resulting in additional pressure drop due to radial flow convergence around the wellbore. $S_{p}$ quantifies the impact of inefficient contact between the well and the fracture, resulting from the choke of the limited contact. Then a $1 / 4$-slope straight line on derivative responses characterizes the pseudo-bilinear flow period. In terms of real variables, Eq. 2.13 becomes 
For oil;

$$
\Delta p_{w f}=\frac{44.1 q B \mu}{h\left(k_{f} w_{f}\right)^{0.5}\left(\phi \mu c_{t} k\right)^{0.25}} \sqrt[4]{t}+\frac{141.2 q B \mu}{k h} s_{p}\left(F_{C D}, h_{D}\right)
$$

For gas;

$\Delta m(p)=\frac{444.75 q T}{h\left(k_{f} w\right)^{0.5}\left(\emptyset \mu c_{t} k\right)^{0.25}} \sqrt[4]{t}+\frac{1424 q T}{k h} S_{p}\left(F_{C D}, h_{D}\right)$

The pseudo-bilinear flow data is analyzed by plotting pressure against the quadratic root of time. The slope of the straight line is given by

$$
m_{b l}=\frac{44.1 q B \mu}{h\left(k_{f} w_{f}\right)^{0.5}\left(\phi \mu c_{t} k\right)^{0.25}}
$$

$k_{f} w_{f}$ can be calculated, provided that reservoir permeability and thickness are known.

The duration of bilinear flow depends on dimensionless fracture conductivity and is given by equations $2.17-2.19$ for a range of dimensionless times and fracture conductivities (John Lee., 1996).

$$
\begin{array}{lll}
t_{D} \approx \frac{0.01}{F_{C D}^{2}}, & F_{C D}>3, \\
t_{D} \approx 0.0205\left(F_{C D}-1.5\right)^{-1.53}, & 1.6 \leq F_{C D} \leq 3, \\
t_{D} \approx\left[\frac{4.55}{\sqrt{F_{C D}}}-2.5\right]^{4}, & F_{C D}<1.6 .
\end{array}
$$

\subsubsection{Formation Linear Flow}

The dimensionless wellbore pressure of a vertical well intercepting a finite-conductivity, vertical fracture during formation linear flow period is given by Cinco-Ley (1978) and Cinco-Ley (1981). In the case of horizontal wells intercepting transverse, finite conductivity fractures, the solution given by Cinco-Ley (1981) can be modified to yield 


$$
p_{\text {Dwell }}=\sqrt{\pi t_{D x f}}+s+s_{p}\left(F_{C D}, x_{f}, h_{D}\right)
$$

Where $S$ is the fracture surface skin and $S_{p}\left(F_{c d}, X_{f}, h_{D}\right)$ is a pseudo-skin factor that accounts for the additional pressure drop due to finite conductivity, flow choking and fracture geometry. The early-time linear flow period is characterized by a half-slope straight line on a log-log plot of the derivative responses. On cartesian co-ordinate paper, $P_{w f}$ is a linear function of $t^{1 / 2}$ (Figure 5).

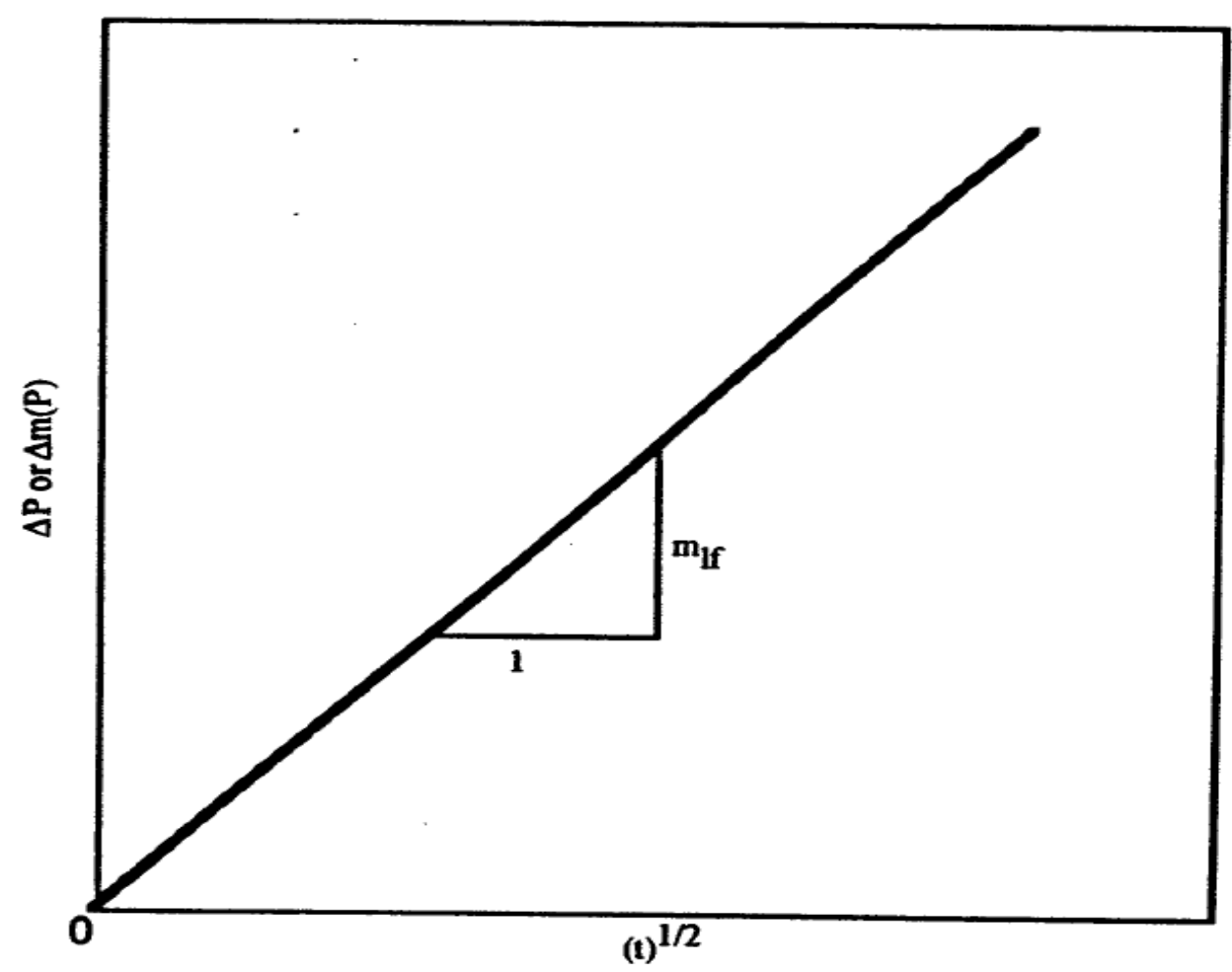

Figure 5 - Linear Flow Graph (After Cinco Ley, 1982)

In dimensional form, equation 2.20 can be written as

For oil;

$$
\Delta p_{w f}=4.0641 \frac{q B}{h x_{f}} \sqrt{\frac{\mu t}{k \phi c_{t}}}+\frac{141.2 q B \mu}{k h}\left[s+s_{p}\left(F_{C D}, x_{f}, h_{D}\right)\right]
$$

For gas;

$\Delta m(p)=\frac{40.93 q T}{h_{f} x_{f}} \sqrt{\frac{t}{\emptyset \mu c_{t} k}}+\frac{1424 q T}{k h} s_{p}\left(F_{C D}, h_{D}\right)$ 
The plot of pressure against square root of time yields a straight line with a slope of

For oil;

$$
m_{f l}=4.0641 \frac{q B}{h x_{f}} \sqrt{\frac{\mu}{k \phi c_{t}}}
$$

For gas;

$m_{f l}=\frac{40.93 T}{k^{0.5} x_{f} h\left(\emptyset \mu c_{t}\right)^{0.5}}$

The linear flow period ends at (John Lee., 1996)

$t_{D} \approx 0.016$

\subsubsection{Pseudo-Radial Flow}

This flow period occurs with fractures of all conductivities. After a sufficiently long flow period, the fracture appears as an expanded wellbore. At this time, the drainage pattern can be considered a circle for practical purposes. The larger the fracture conductivity is, the later the development of an essentially radial drainage pattern is. If the fracture length is large relative to the drainage area, then boundary effects distort or entirely mask the pseudo-radial flow regime. The dimensionless pressure drop during this flow regime is given by Ozkan (2006)

$$
p_{w D}=\frac{1}{2}\left(\ln \frac{t_{D}}{r_{w D}^{2}}+0.80907\right)+s+s_{p}\left(F_{C D}, x_{f}, h_{D}\right)
$$

In dimensional form, it is given by

$$
\Delta p_{w f}=\frac{162.6 q B \mu}{k h}\left[\log \left(\frac{2.64 \times 10^{-4} k t}{\phi \mu c_{t} r_{w}^{\prime 2}}\right)+\frac{s+s_{p}\left(F_{C D}, x_{f}, h_{D}\right)}{1.1516}+0.3513\right]
$$

The formation permeability can be obtained from the slope of the semi-log straight line during pseudo-radial flow given by 
For oil;

$$
m_{p r}=\frac{162.6 q B \mu}{k h}
$$

For gas;

$$
m_{p r}=\frac{1637 q T}{k h}
$$

The pseudo-radial flow period ends at (John Lee., 1996)

$$
t_{D} \approx 3
$$




\section{CHAPTER 3: METHODOLOGY}

\subsection{Overview}

The methodology developed in this study uses early time production data together with bottom hole pressure measurements and basic reservoir and fluid properties as input. The desired output results are reliable estimates of shale matrix permeability and an average fracture half-length. Figure 6 gives an overview of the methodology used in this study.

Input
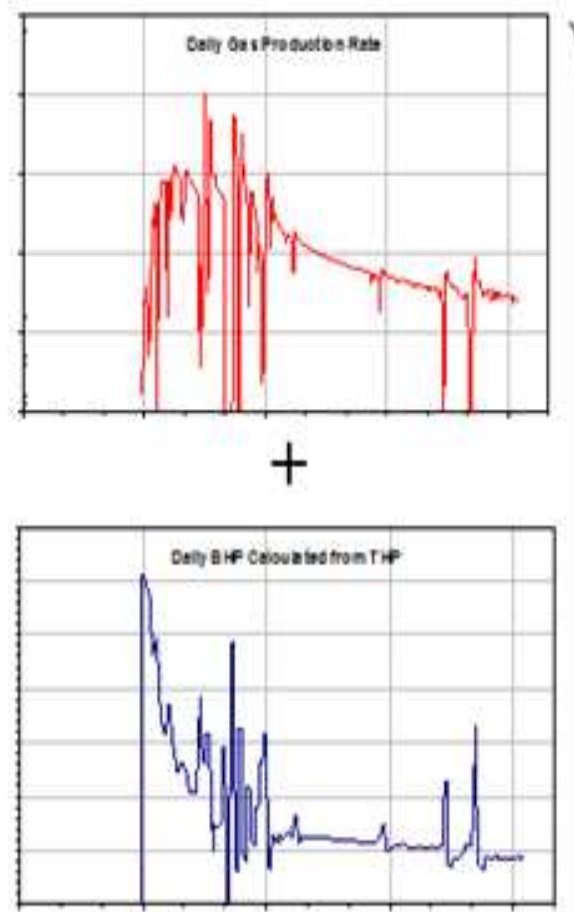

$+$

Reservoir/Well Information

\section{Output}

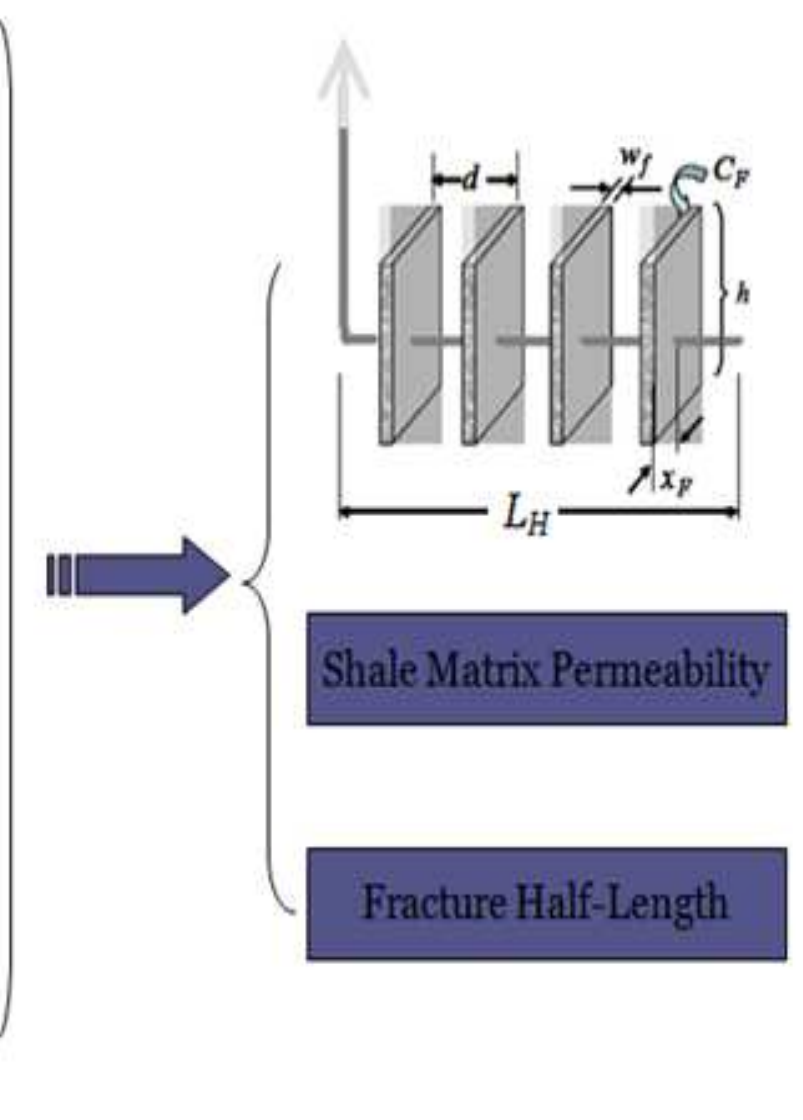

Figure 6 - An Overview of Methodology 


\subsection{Reservoir Model of Study}

For the purpose of this research work, a horizontal well with multiple transverse hydraulic fractures is considered. Each of the transverse hydraulic fractures is considered to be a rectangular parallelepiped porous medium of dimension $2 \mathrm{x}_{\mathrm{f}} \mathrm{x}_{\mathrm{f}} \mathrm{x} \mathrm{w}_{\mathrm{f}}$ as shown in figure 7. The fractures have a half-length of $x_{f}$ and width of $w_{f}$ and penetrate the entire thickness, $\mathrm{h}$ of the formation. The hydraulic fractures are separated by a distance $\mathrm{d}$ (ft) along a horizontal well length $\mathrm{L}_{\mathrm{H}}(\mathrm{ft})$. At long times, a multiply fractured horizontal well behaves like a single fracture between the two outermost fractures along the horizontal well (Chen, 1997., Raghavan and Chen, 1997). Under the conditions assumed in this study, there is no pressure loss along the horizontal wellbore and therefore the pressure transient response of a horizontal well with $\mathrm{n}_{\mathrm{F}}$ identical fractures can be modeled by considering one of the fractures producing from a rectangular reservoir section at a rate equal to $q_{g}=q_{t} / n_{F}$ where $q_{t}$ is the total flow rate of the horizontal well.

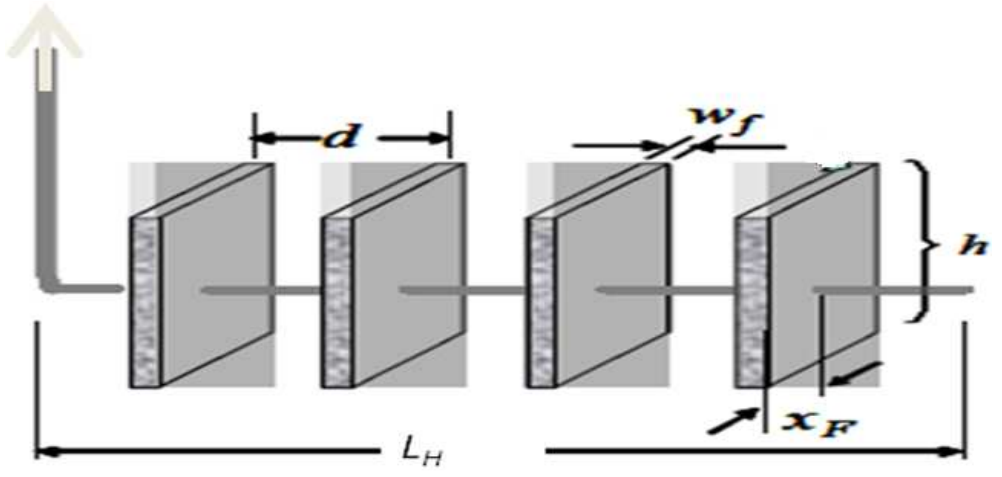

Figure 7 - The Reservoir Model of Study

\subsection{Formation Linear Flow Solution}

The methodology employed in this study is to develop a set of working equations applied to the analysis of the early time production data obtained during the linear flow period. These equations are developed from the conventional pressure transient analysis equations for formation linear flow in vertical wells.

For gas, the linear flow solution in terms of pseudo-pressure is given by

$$
\Delta m(p)=\frac{40.93 q T}{h_{f} x_{f}} \sqrt{\frac{t}{\emptyset \mu c_{t} k}}+\frac{1424 q T}{k h} S_{p}\left(F_{C D}, h_{D}\right)
$$


The dimensionless pressure (John Lee., 1996) can be defined as;

$p_{D}=\frac{k h}{1424 q T} \Delta m(p)$

The dimensionless time with fracture half length as the characteristic length (John Lee., 1996) is defined as;

$t_{D}=\frac{0.0002637 k t}{\emptyset \mu c_{t} x_{f}^{2}}$

The working equation for Linear Flow analysis in hydraulically fractured wells is

$x_{f} k^{0.5}=\frac{40.93 q_{g} T}{m h}\left(\frac{1}{\emptyset \mu c_{t}}\right)^{0.5}$

From literature (John Lee., 1996), formation linear flow ends at a dimensionless time given by

$t_{\text {Delf }}=0.016$

Substituting equation (3.3) into (3.1), we have

$\frac{0.0002637 k t_{e l f}}{\varnothing \mu c_{t} x_{f}^{2}}=0.016$

Equation (3.4) can be re-arranged as

$x_{f}=0.128 \sqrt{t_{e l f}}\left(\frac{k}{\emptyset \mu c_{t}}\right)^{0.5}$

And

$k^{0.5}=\frac{x_{f}}{0.128\left(\frac{t_{\text {elf }}}{\emptyset \mu c_{t}}\right)^{0.5}}$ 
Substituting equations (3.5) and (3.6) into equation (3.2), we can obtain fracture half length as

$x_{f}=2.289 t_{e l f}^{0.25}\left(\frac{q_{g} T}{m h} \frac{1}{\emptyset \mu c_{t}}\right)^{0.5}$

And formation permeability as

$k=\frac{319.77 q_{g} T}{m h \sqrt{t_{e l f}}}$

Where;

$t_{D}=$ dimensionless time

$P_{D}=$ dimensionless pressure

$t_{\text {elf }}=$ end of formation linear flow period (hrs)

$q_{g}=$ constant gas flow rate (Mscf/Day)

$T=$ formation temperature (deg. R)

$h=$ formation thickness $(\mathrm{ft})$

$k=$ formation permeability (md)

$x_{f}=$ fracture half length $(\mathrm{ft})$

$\varnothing=$ porosity (fraction)

$\mu=$ gas viscosity (cp)

$c_{t}=$ gas compressibility $(1 / \mathrm{psi})$

$m=$ slope of the straight line on a plot of pressure draw down vs. square root of time $\left(\mathrm{t}^{1 / 2}\right)$

$F_{c d}=$ dimensionless fracture conductivity

$s_{p}=$ pseudo skin

$h_{D}=$ dimensionless reservoir thickness

\subsection{Procedure}

The following provides an outline of the newly developed technique to reliably estimate fracture properties from a hydraulically fractured horizontal well completed in shale gas reservoir.

\section{Step - 1:}

Identify the existing flow regimes from a diagnostic plot of pressure derivative versus time. If linear flow is present, then identify the beginning and the end of linear flow period $\left(t_{e l f}\right)$. 


\section{Step - 2:}

Estimate the slope $\mathrm{m}$ of the linear plot of pseudo-pressure drawdown, $\Delta m(p)$, versus $t^{1 / 2}$, for the data in the range of the linear flow period.

\section{Step - 3:}

Apply the derived linear flow equations (3.7) and (3.8):

$x_{f}=2.289 t_{\text {elf }}^{0.25}\left(\frac{q_{g} T}{m h} \frac{1}{\emptyset \mu c_{t}}\right)^{0.5}$

And

$k=\frac{319.77 q_{g} T}{m h \sqrt{t_{e l f}}}$ 


\section{CHAPTER 4: VALIDATION}

\subsection{Validation of Methodology}

In order to validate the proposed methodology, two synthetic cases are generated by reservoir simulation, and variable production rates and pressure data for a well are converted into an equivalent constant-rate pressure drawdown test using a stable deconvolution technology. The input parameters for the reservoir simulation run are presented in Tables 2 and 3.

\subsubsection{Synthetic Case - 1:}

The basic information for the reservoir, fracture and fluid properties for synthetic case 1 are given in table 2 below.

Table 2-Reservoir Simulation Model Input Parameters (Synthetic Case - 1)

\begin{tabular}{|c|c|}
\hline \multicolumn{2}{|c|}{ Reservoir Properties } \\
\hline Reservoir dimensions (ft) & $3600 \times 1938 \times 120$ \\
\hline Thickness (ft) & 120 \\
\hline Initial reservoir pressure (psia) & 2864 \\
\hline Reservoir Temperature (deg. F) & 125 \\
\hline Porosity & 0.08 \\
\hline Shale matrix permeability (nd) & 500 \\
\hline \multicolumn{2}{|c|}{$\begin{array}{ll}\text { Fluid Properties } \\
\end{array}$} \\
\hline Viscosity (cp) & 0.0203 \\
\hline Compressibility (1/psi) & 0.0003171 \\
\hline Gas gravity & 0.65 \\
\hline \multicolumn{2}{|c|}{ Fracture Parameters } \\
\hline No. of fractures & 8 \\
\hline Fracture spacing (ft) & 415 \\
\hline Fracture half-length (ft) & 500 \\
\hline \multicolumn{2}{|c|}{ Well Data } \\
\hline Horizontal lateral length (ft) & 3050 \\
\hline
\end{tabular}

Figure 8 shows the well, fractures and reservoir system for synthetic case 1 while Figures 9 and 10 show the daily production rate and cumulative gas production for the horizontal well considered. 


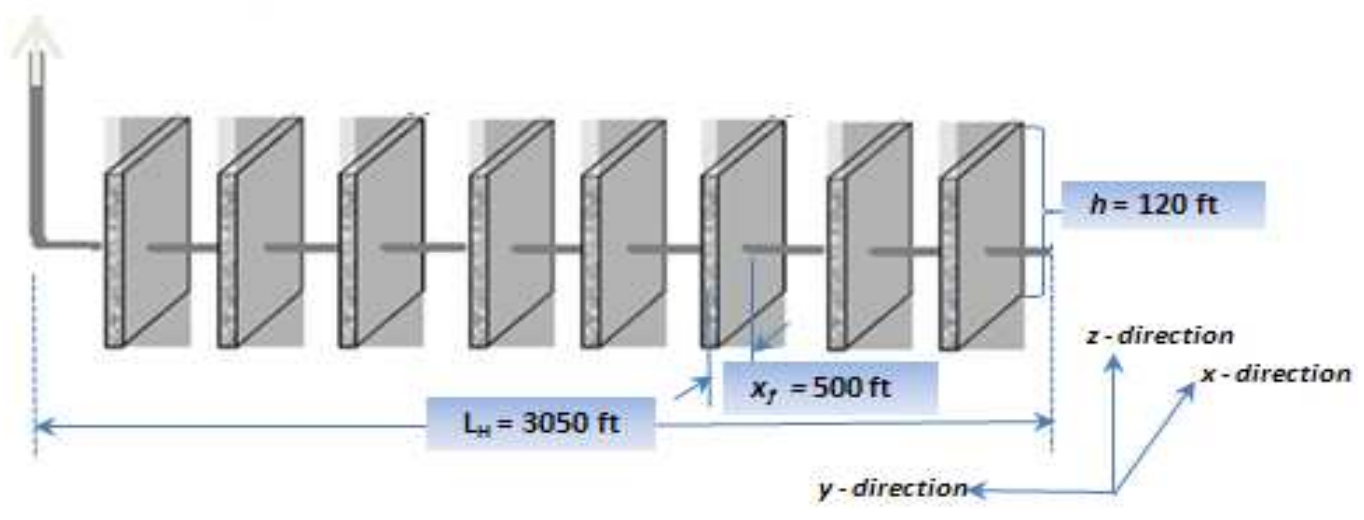

Figure 8 - The well, fractures and reservoir model for synthetic case 1

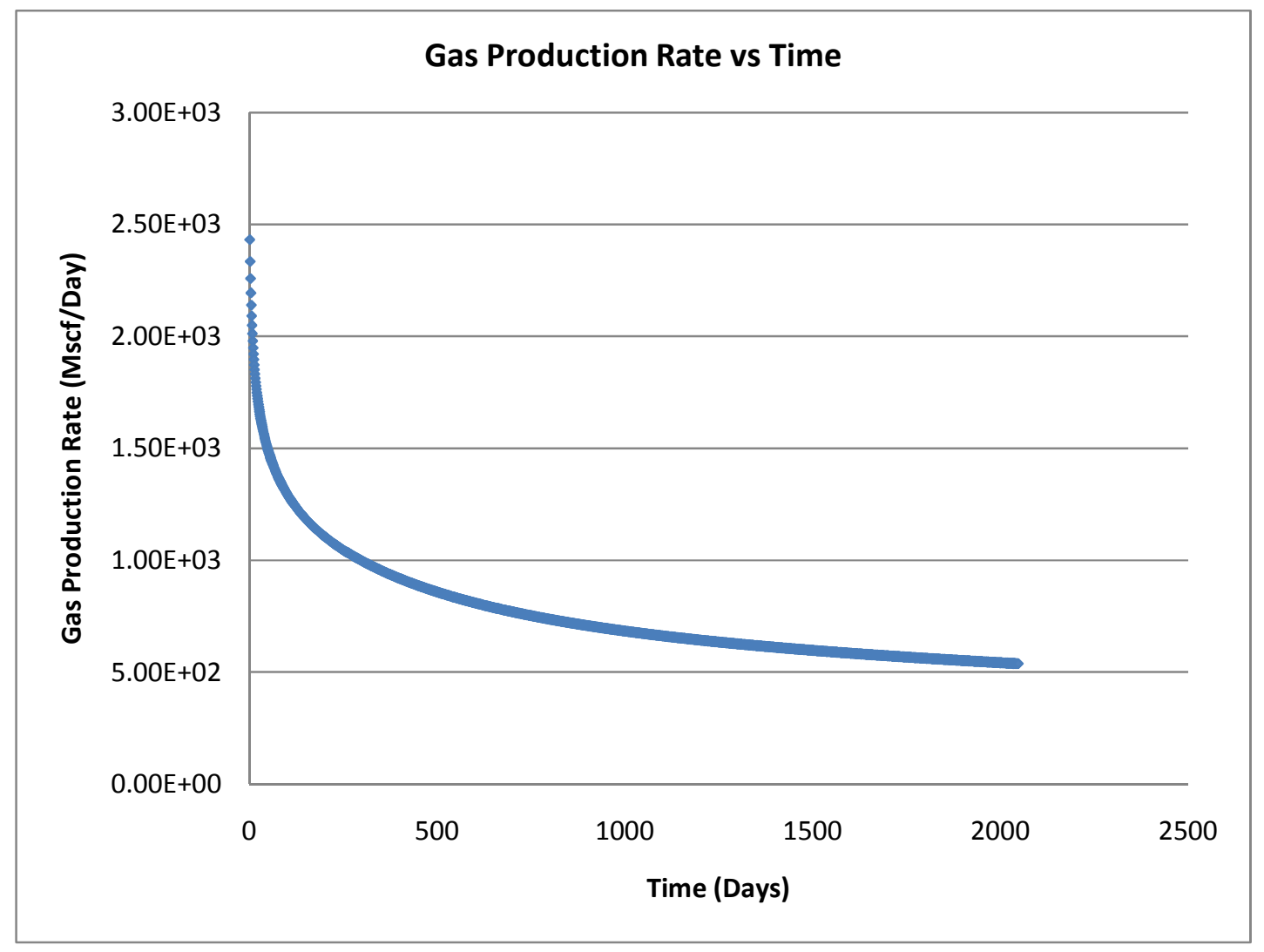

Figure 9 - Production Performance Curve for Synthetic Case-1

Using a stable deconvolution technology, the variable production rate-pressure data obtained from the simulation run was converted into an equivalent constant-rate pressure draw down test. This corresponds to an equivalent constant rate of $80 \mathrm{Mscf} / \mathrm{day}$. 


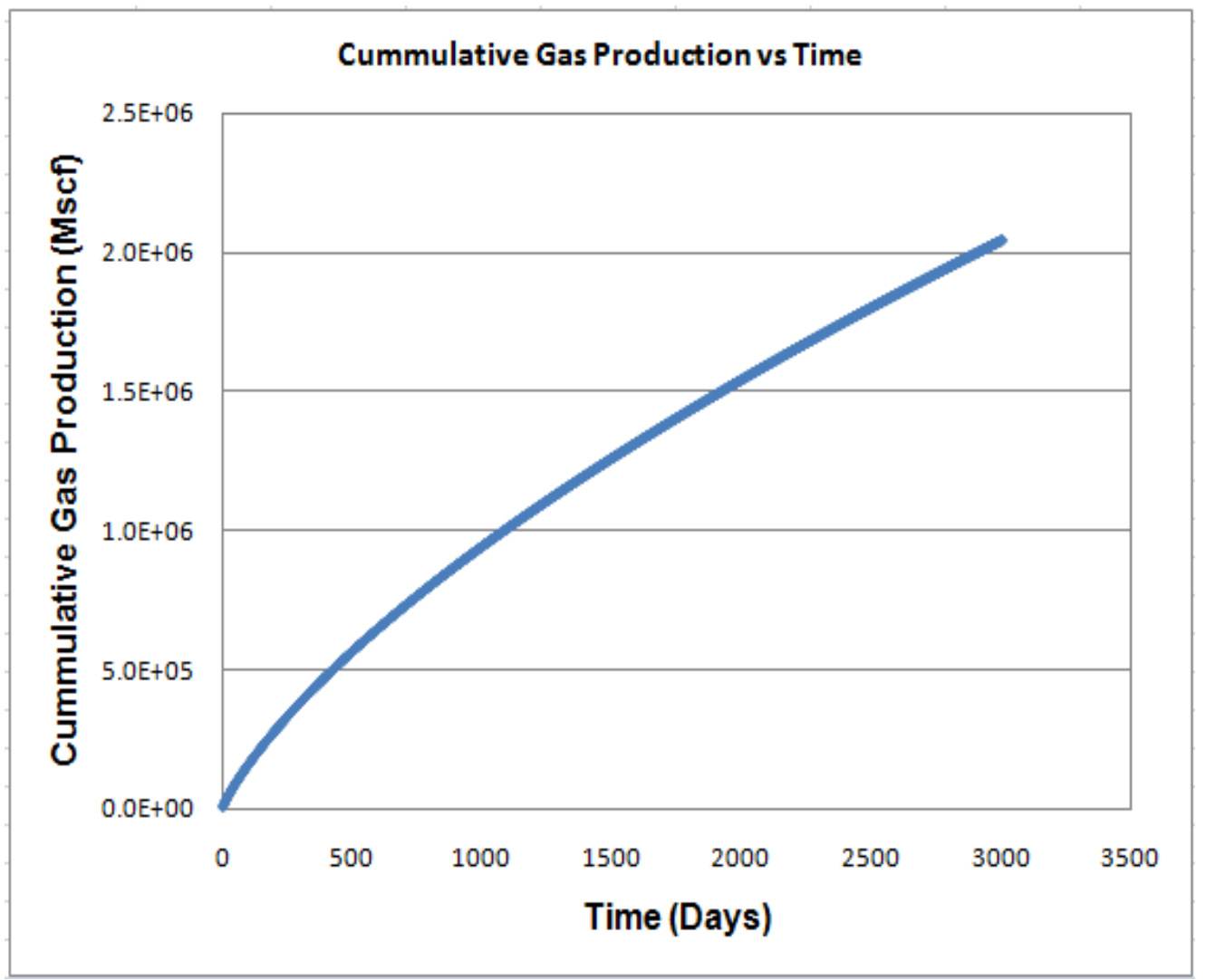

Figure 10 - Cumulative Gas Production vs. Time for Synthetic Data Case-1

\subsubsection{Application of developed method to Synthetic Case - 1}

Following the steps outlined in section 3.4 of the previous chapter, the existing flow regimes are identified from a diagnostic plot of pressure derivative versus time as shown in Figure 11.

From the plot, the following information can be obtained:

- Linear flow period exists with a one-half slope on the pressure derivative plot

- Start of linear flow $\left(t_{s l f}\right)$ is approximately $6000 \mathrm{hrs}$

- End of linear flow $\left(t_{e l f}\right)$ is about $15216 \mathrm{hrs}$ 


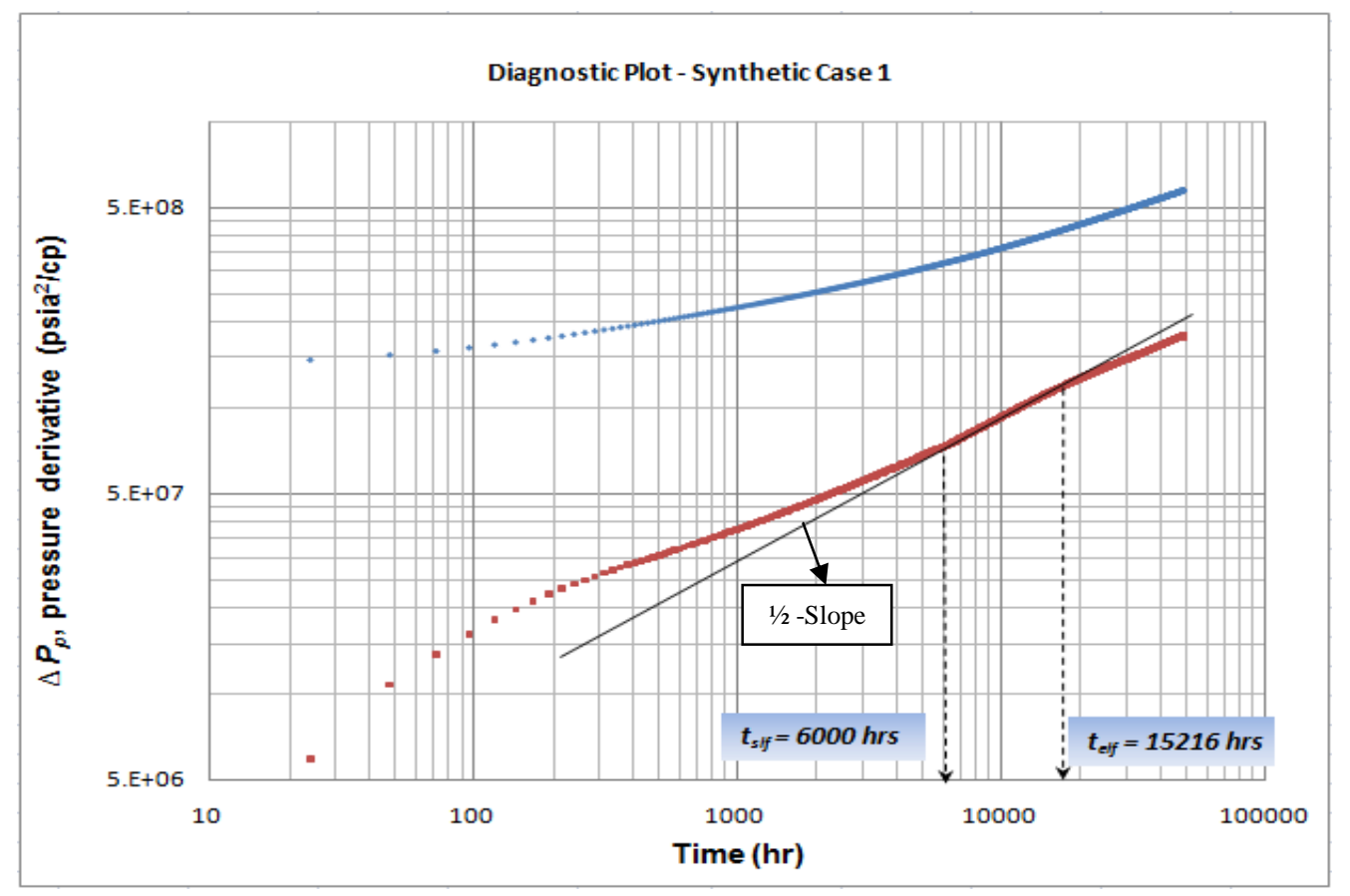

Figure 11 - Diagnostic Plot for Synthetic Case - 1

Figure 12 shows the linear plot of pseudo-pressure drawdown, $\Delta m(p)$ versus $t^{1 / 2}$, for the data in the range of the linear flow period $(6000-15216 \mathrm{hrs})$.

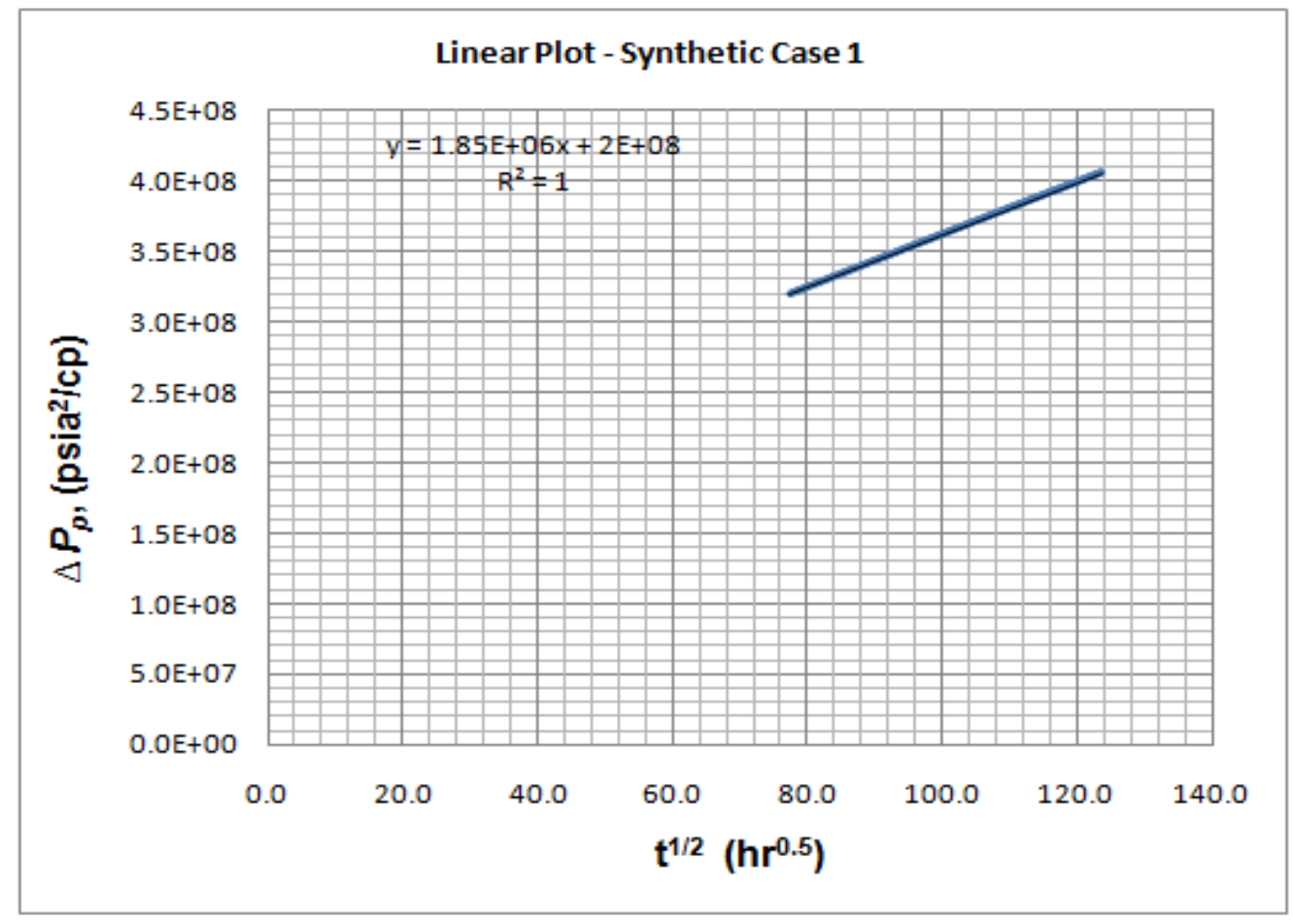

Figure 12 - Specific Linear Plot of Pseudo-Pressure Drawdown vs. $t^{1 / 2}$ for Synthetic Case - 1 
From the linear plot, slope $m=1.85 \times 10^{6} \mathrm{psi}^{2} / \mathrm{cp} / \mathrm{hr}^{0.5}$

The derived linear flow equations are then applied to estimate fracture half-length and shale matrix permeability. Using equations (3.7) and (3.8), with the estimated values of the ending time of linear flow $\left(t_{e l f}\right)$ and slope $(m)$, and the basic reservoir properties for synthetic case-1, estimates of fracture half-length and matrix permeability can be obtained as:

$$
k=\frac{319.77 q_{g} T}{m h \sqrt{t_{e l f}}}=\frac{319.77 \times 80 \times(125+460)}{1.85 \times 10^{6} \times 120 \times \sqrt{15216}}=\mathbf{5 . 4 6 \times 1 0 ^ { - 4 }} \mathbf{m d}(546 \mathrm{nd})
$$

And

$$
\begin{aligned}
x_{f}= & 2.289 t_{\text {elf }}^{0.25}\left(\frac{q_{g} T}{m h} \frac{1}{\emptyset_{\mu c_{t}}}\right)^{0.5} \\
& =2.289 \times 15216^{0.25} \times\left(\frac{80 \times(125+460)}{\left(1.85 \times 10^{6} \times 120\right)} \times \frac{1}{(0.08 \times 0.0203 \times 0.0003171)}\right)^{0.5} \\
& =\mathbf{5 1 4 . 3 7} \mathbf{f t}
\end{aligned}
$$

\subsubsection{Synthetic Case - 2:}

The basic information for the reservoir, fracture and fluid properties for synthetic case 2 are presented in table 3 below.

Table 3 - Reservoir Simulation Model Input Parameters (Synthetic Case - 2)

\begin{tabular}{|l|c|}
\hline \multicolumn{2}{|c|}{ Reservoir Properties } \\
\hline Reservoir dimensions (ft) & $3640 \times 962 \times 120$ \\
\hline Thickness (ft) & 120 \\
\hline Initial reservoir pressure (psia) & 2864 \\
\hline Reservoir Temperature (deg. F) & 125 \\
\hline Porosity & 0.08 \\
\hline Shale matrix permeability (nd) & 250 \\
\hline \multicolumn{2}{|c|}{ Fluid Properties } \\
\hline Viscosity (cp) & 0.0203 \\
\hline Compressibility (1/psi) & 0.0003171 \\
\hline Gas gravity & 0.65 \\
\hline \multicolumn{2}{|c|}{} \\
\hline No. of fractures & 32 \\
\hline Fracture spacing (ft) Pell Data & 105 \\
\hline Fracture half-length (ft) & 250 \\
\hline \multicolumn{2}{|c|}{} \\
\hline Lateral length (ft) & 3360 \\
\hline
\end{tabular}


Figure 13 shows the well, fractures and reservoir system for synthetic case 2 while Figures 14 and 15 show the daily production rate and cumulative gas production for the horizontal well considered.

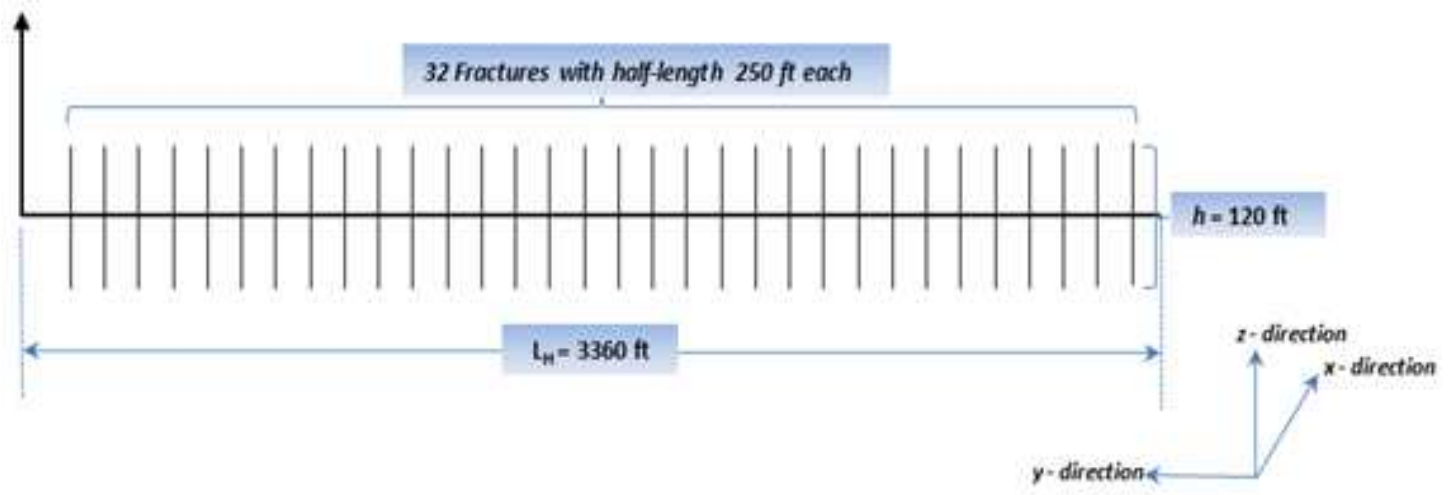

Figure 13 - The well, fractures and reservoir model for synthetic case 2

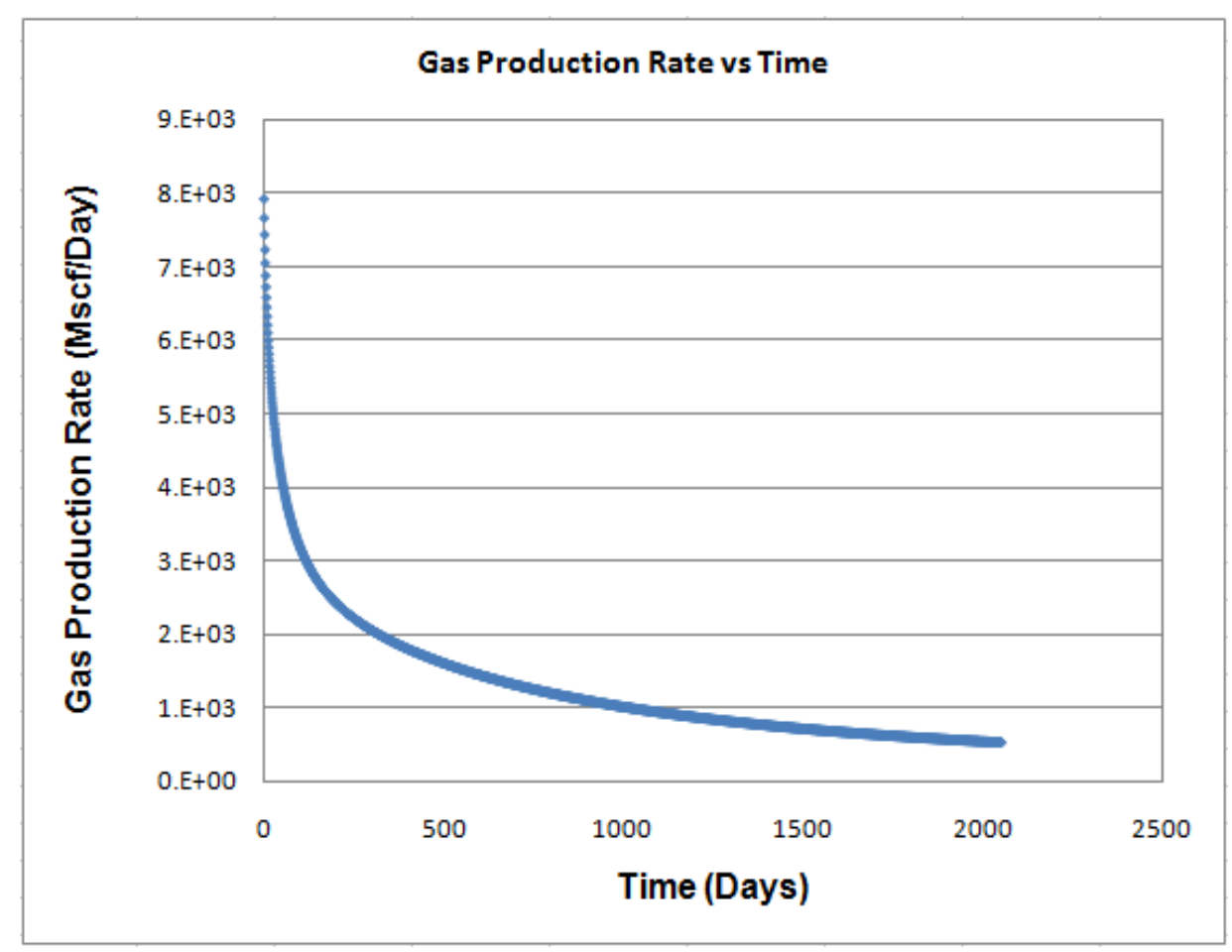

Figure 14 - Production Performance Curve for Synthetic Case-2

Using a stable deconvolution technology, the variable production rate-pressure data obtained from the simulation run was converted into an equivalent constant-rate pressure draw down test. This corresponds to an equivalent constant rate of $30 \mathrm{Mscf} / \mathrm{day}$. 


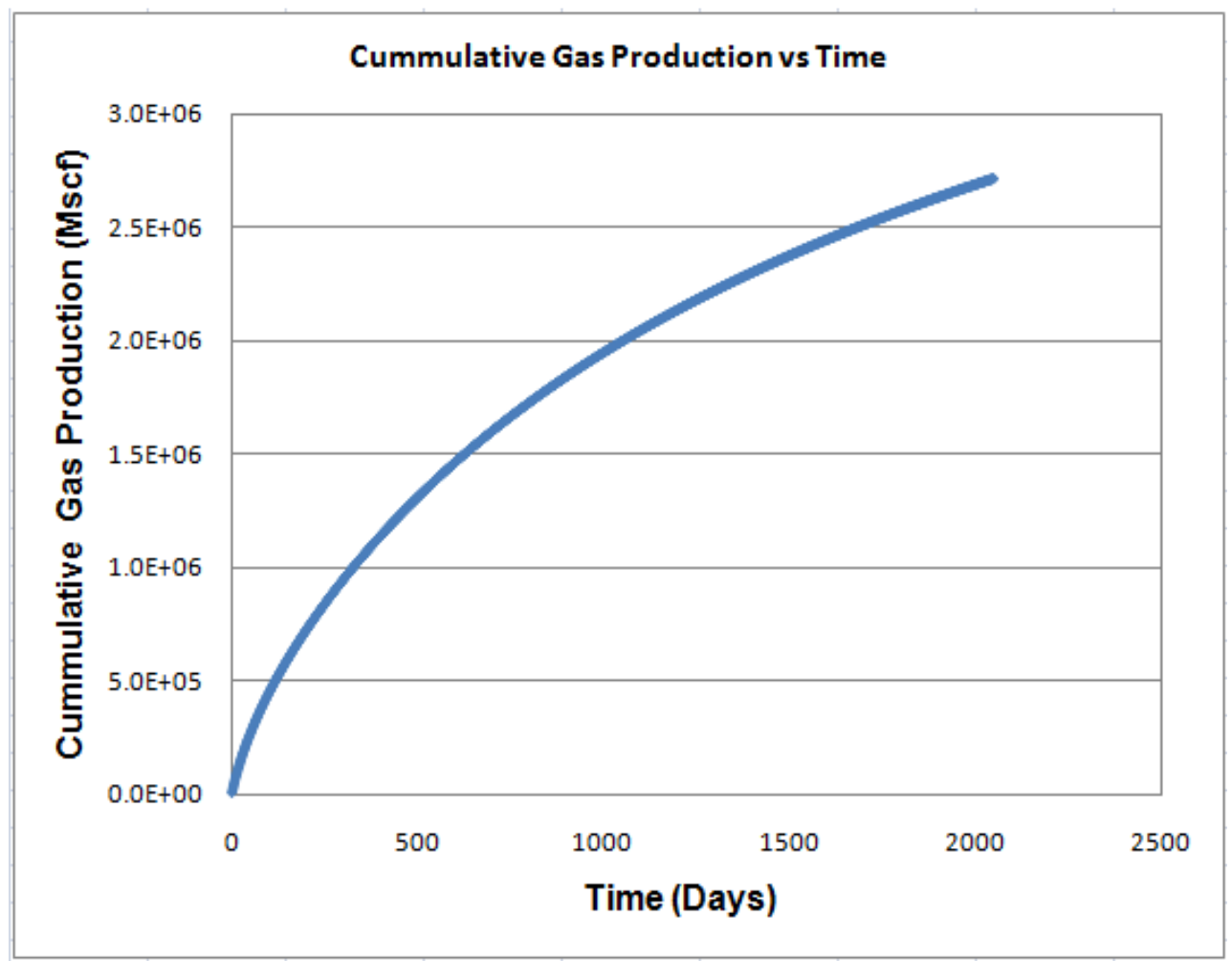

Figure 15 - Cumulative Gas Production vs. Time for Synthetic Case-2

\subsubsection{Application of developed method to Synthetic Case - 2}

Following the steps outlined in section 3.4 of the previous chapter, the existing flow regimes are identified from a diagnostic plot of pressure derivative versus time as shown in Figure 16. From the plot, the following information can be obtained:

- Linear flow period exists with a one-half slope on the pressure derivative plot

- Start of linear flow $\left(t_{s / f}\right)$ is around $600 \mathrm{hrs}$

- End of linear flow $\left(t_{e l f}\right)$ is approximately $9000 \mathrm{hrs}$ 


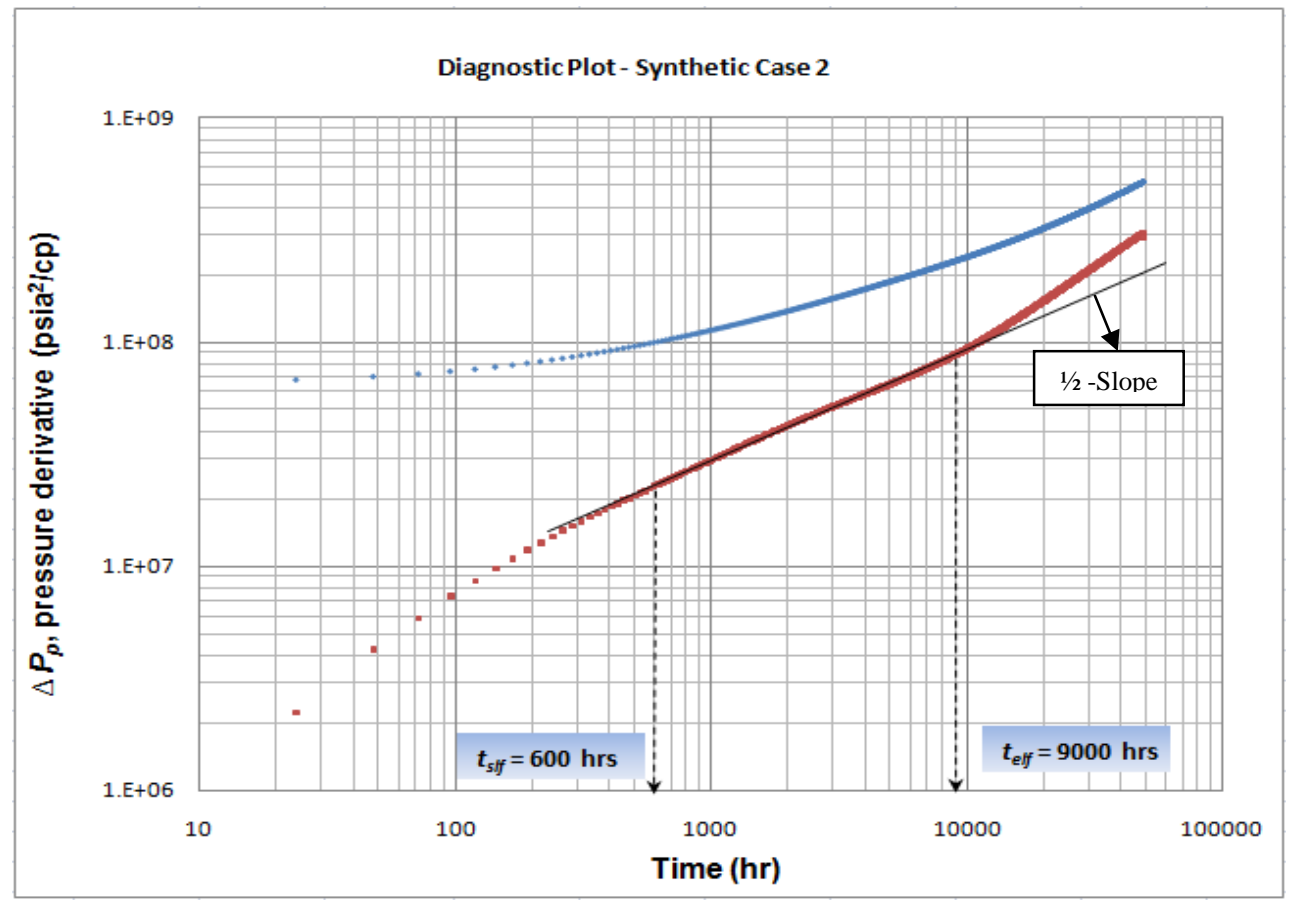

Figure 16 - Diagnostic Plot for Synthetic Case - 2

For the data in the range of the linear flow period $(600-9000 \mathrm{hrs})$, a linear plot of pseudo-pressure drawdown, $\Delta m(p)$ versus $t^{1 / 2}$ (as shown in Figure 17) gives an estimate of the slope $(m)$.

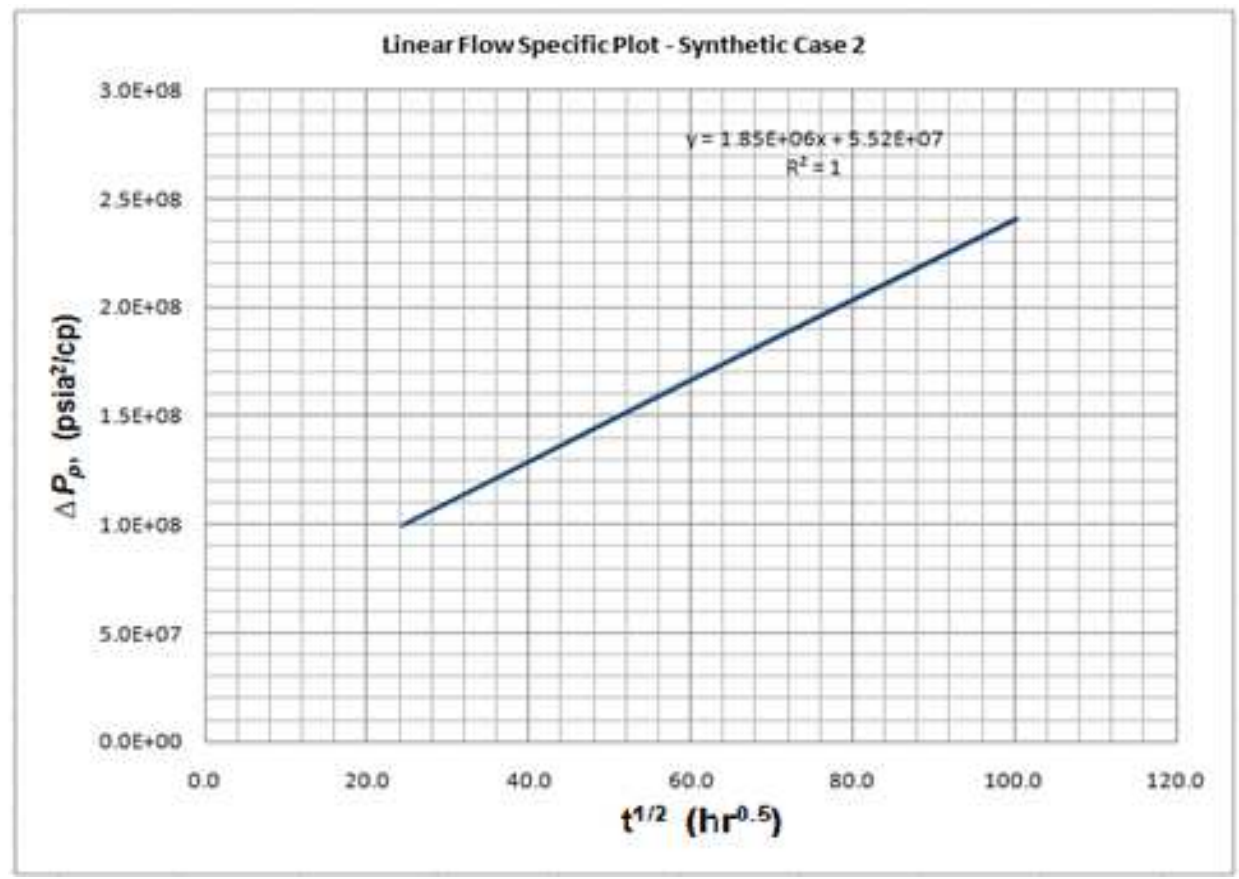

Figure 17 - Specific Linear Plot of Pseudo-Pressure Drawdown vs. $t^{1 / 2}$ for Synthetic Case -2. 
From the linear plot, slope $m=1.85 \times 10^{6} \mathrm{psi}^{2} / \mathrm{cp} / \mathrm{hr}^{0.5}$

The derived linear flow equations are then applied to estimate fracture half-length and shale matrix permeability. Using equations (3.7) and (3.8), with the estimated values of the ending time of linear flow $\left(t_{e l f}\right)$ and slope $(m)$, and the basic reservoir properties for synthetic case 2 , estimates of fracture half-length and matrix permeability can be obtained as:

$k=\frac{319.77 q_{g} T}{m h \sqrt{t_{e l f}}}=\frac{319.77 \times 30 \times(125+460)}{1.85 \times 10^{6} \times 120 \times \sqrt{9000}}=\mathbf{2 . 6 6} \times \mathbf{1 0}^{-4} \mathbf{m d}(266 \mathrm{nd})$

And

$$
\begin{aligned}
x_{f} & =2.289 t_{\text {elf }}^{0.25}\left(\frac{q_{g} T}{m h} \frac{1}{\emptyset_{\mu c_{t}}}\right)^{0.5} \\
& =2.289 \times 9000^{0.25} \times\left(\frac{30 \times(125+460)}{\left(1.85 \times 10^{6} \times 120\right)} \times \frac{1}{(0.08 \times 0.0203 \times 0.0003171)}\right)^{0.5} \\
& =\mathbf{2 7 6 . 2 3 ~ f t}
\end{aligned}
$$

\subsection{Results Summary (Synthetic Case - 1)}

Table 4 compares the true values with the estimated values for both matrix permeability and fracture half length.

Table 4 - Comparison between the true values and the estimated values (Synthetic Case - 1)

\begin{tabular}{|c|c|c|}
\hline Parameter & True Value & Estimated Value \\
\hline Shale Matrix Permeability (nd) & 500 & 546 \\
\hline Fracture Half-length (ft) & 500 & 514 \\
\hline
\end{tabular}

From the results provided in table 4 , the newly developed method provides close estimates of both shale matrix permeability and fracture half-length.

\subsection{Results Summary (Synthetic Case - 2)}

Table 5 compares the true values with the estimated values for both matrix permeability and fracture half length. 
Table 5 - Comparison between the true values and the estimated values (Synthetic Case - 2)

\begin{tabular}{|c|c|c|}
\hline Parameter & True Value & Estimated Value \\
\hline Shale Matrix Permeability (nd) & 250 & 266 \\
\hline Fracture Half-length (ft) & 250 & 276 \\
\hline
\end{tabular}

The results obtained from synthetic case -2 also show that the newly proposed method provides close estimates of both shale matrix permeability and fracture half-length.

To reliably check the validity of the new method, different well - fracture configurations have been considered in this study. The two cases presented in this study have different number of transverse fractures, fracture spacing, fracture half length and shale matrix permeability. For synthetic case -1 , a horizontal well with 8 fractures spaced $415 \mathrm{ft}$ apart, over a $3050 \mathrm{ft}$ lateral length was considered. Each fracture has a half length of 500 $\mathrm{ft}$ and the shale matrix permeability is $500 \mathrm{nd}$. For synthetic case -2 , a horizontal well with 32 fractures spaced $105 \mathrm{ft}$ apart, over a $3360 \mathrm{ft}$ lateral well length was considered. Each fracture has a half length of $250 \mathrm{ft}$ and the shale matrix permeability is $250 \mathrm{nd}$. 


\section{CHAPTER 5: CONCLUSIONS \& RECOMMENDATIONS}

The technique presented in this research work provides a reliable estimate of both fracture half-length and shale matrix permeability using the production data acquired during the linear flow period. A pre-knowledge of the formation permeability is not a pre-requisite to use this method. Since this method uses only the early time production data, it reduces the impractical long times required for gas well testing in hydraulically fractured horizontal wells in shale gas reservoirs. It therefore provides an excellent alternative to the conventional pressure transient analysis method.

This study has shown that the newly developed method provides very close estimates of average fracture half-length and shale matrix permeability. The results obtained from the study show an estimation error of about $2 \%-10 \%$ when this method is used. This method is therefore useful in pressure transient analysis of horizontal wells with multiple hydraulic fractures in shale gas reservoirs. 


\section{REFERENCES}

ZERZAR, A., Sonatrach; TIAB, D., U. Oklahoma \& Y. BETTAM, Sonatrach. (2004). Interpretation of Multiple Hydraulically Fractured Horizontal Wells. SPE 88707 .

Ameri, S., Aminian, K., Miller, J.A., Doricich, D., West Virginia University.; Yost II, A.B., U.S. DOE/METC (1985). A Systematic Approach for Economic Development of the Devonian Shale Gas Resources. SPE 14504.

API Energy (2010, February 01). Policy Issues. Retrieved April 20, 2010, from Energy API: http://www.api.org/policy/exploration/hydraulicfracturing/shale_gas.cfm

Aziz. K., J. Wan., Stanford University (1999). Multiple Hydraulic Fractures in Horizontal Wells. SPE 54627 .

Brian Gault., Garth Stotts. (2007, March 1). Improve Shale Gas Production Forecasts. Retrieved May 20, 2010, from Hart E \& P: www.epmag.com/archives/features/360.htm

Brown M. SPE, and E. Ozkan, SPE, Colorado School of Mines; Raghavan R., SPE, Phillips Petroleum Co., and Kazemi H., SPE, Colorado School of Mines. (2009).

Practical Solutions for Pressure Transient Responses of Fractured Horizontal Wells in Unconventional Reservoirs. SPE 125043.

Chen Chih-Cheng, Rajagopal Raghavan., (1997). A Multiply-Fractured Horizontal Well in a Rectangular Drainage Region. Society of Petroleum Engineers Journal. Vol. 2 , 455465.

Cheng, Y. (2003). Pressure Transient Testing and Productivity Analysis for Horizontal Wells. PhD.Thesis. Texas A \& M University.

Cinco Ley, H. (1982). Evaluation of Hydraulic Fracturing by Transient Pressure Analysis Methods. SPE 10043. Presented at International Petroleum Exhibition and Technology Symposium, Beijing, China.

Cinco-Ley H., a. S. (Sept. 1981). Transient Pressure Analysis for Fractured Wells. JPT , 1749-1766.

Cinco-Ley H., S. V. (August 1978). Transient Pressure Behavior for a Well with Finite Conductivity Vertical Fracture. SPEJ , 253-264.

Cinco-ley, Heber, Stanford U.; Samaniego-V., Fernando, Inst. Mexicano del Petroleo. (1977). Effect of Wellbore Storage and Damage on the Transient Pressure Behavior of Vertically Fractured Wells. SPE 6752 .

Clarkson, C.R., U. of Calgary, Jordan, C.L, BOE Solutions Inc; IIk, D. and Blasingame, T.A., Texas A \& M University (2009). Production Data Analysis of Fractured and Horizontal CBM Wells. SPE 125929. 
Clonts, M.D., ARCO Alaska Inc.; Ramey Jr., H.J., Stanford U. (April 1986). Pressure Transient Analysis for Wells with Horizontal Drainholes. SPE 15116.

Daniel Arthur, J. P., Brian Bohm, P. A., and Mark Layne, P. P. (2008). Hydraulic Fracturing Considerations for Natural Gas Wells of the Marcellus Shale. The Ground Water Protection Council. 2008 Annual Forum .

Daniel Arthur, J., SPE, Brian Bohm, Bobbi Jo Coughlin, and Mark Layne, SPE, ALL Consulting. (2009). Evaluating the Environmental Implications of Hydraulic Fracturing in Shale Gas Reservoirs. SPE 121038.

David Alleman., ALL Consulting, Daniel J. Arthur, P.E., ALL Consulting, Bruce Langhus, P.G., PhD., ALL Consulting (2008). An Overview of Modern Shale Gas Development in the United States. ALL Consulting.

Davlau, F., Mouronval, G., Bourdarot, G., Elf Aquitaine (Production) (1985). Pressure Analysis for Horizontal Wells. SPE 14251.

Medeiros, F., (2007). Pressure-Transient Performances of Hydraulically Fractured Horizontal Wells in Locally and Globally Naturally Fractured Formations. IPTC 11781.

Gringarten A.C., U. of California; Ramey Jr., H.J., Raghavan, R., Stanford University (1975). Applied Pressure Analysis for Fractured Wells. J.Pet.Tech, 887-892.

Gunter J. Lichtenberger, SPE, Oryx Energy Co., (1994). Data Aquisition and Interpretation of Horizontal Well Pressure-Transient Tests. JPT .

Horne R. N., Stanford. U; Temeng, K.O., Saudi Aramco. (1995). Relative Productivities and Pressure Transient Modeling of Horizontal Wells with Multiple Fractures. SPE 29891 .

John Lee., Wattenbarger, R.A, (1996). Gas Reservoir Engineering. SPE Textbook Series Vol. 5. Society of Petroleum Engineers.

Larsen L., (1991). Pressure-Transient Behavior of Horizontal Wells with FiniteConductivity Vertical Fractures. SPE 22076.

Larsen, Leif, Statoil A/S; Hegre, T.M., Petec A/S. (1994). Pressure-Transient Analysis of Multifractured Horizontal Wells. SPE 28389.

Al-Kobaisi, M., Ozkan, E., Kazemi, H., Ramirez, B., Colorado School of Mines (PETSOC 2006-162). Pressure Transient Analysis of Fractured Horizontal Wells with Transverse, Finite Conductivity Fractures. Canadian International Petroleum Conference.

Mukherjee, Hemanta, Economides, Michael J., Dowell Schlumberger (1991). A Parametric Comparison of Horizontal and Vertical Well Performance. SPE 18303.

Ozkan E. (1988). Performance of Horizontal Wells. PhD. The University of Tulsa. 
Prats M., Shell Development Co. (1961). Effects of Vertical Fractures on Reservoir Behavior - Incompressible Fluid Case. SPE 1575-G.

Raghavan R., Chih-Cheng Chen, Bijan Agarwal. (1997). An Analysis of Horizontal Wells Intercepted by Multiple Fractures. SPE 27652.

Schulte, W.M., Koninklijke., Shell E and P Laboratorium. (Sept. 1986). Production From a Fractured Well with Well Inflow Limited to Part of the Fracture Height. SPE 12882.

Serra K., U. of Tulsa; Reynolds, A.C., U. of Tulsa; Raghavan, R., U. of Tulsa (1983). New Pressure Transient Analysis Methods for Naturally Fractured Reservoirs. SPE 10780-PA

Soliman M.Y., Hunt. James, L., El Rabaa, A.M, Halliburton Services (1990). Fracturing Aspects of Horizontal Wells. SPE 18542-PA.

Yost II, A.B., U.S DOE/METC; Overbey Jr., W.K., BDM Engineering Services Co. (1989). Production and Stimulation Analysis of Multiple Hydraulic Fracturing of a 2,000 ft Horizontal Well. SPE 19090. 


\section{NOMENCLATURE}

$B=$ Formation volume factor, $\mathrm{rbbl} / \mathrm{stb}$

$c_{t}=$ Total compressibility of the reservoir, $\mathrm{psi}^{-1}$

$D=$ Dimensionless

$d=$ Fracture spacing, $\mathrm{ft}$

$F_{c d}=$ Dimensionless fracture conductivity

$h=$ Reservoir thickness, $\mathrm{ft}$

$h_{f}=$ Fracture height, $\mathrm{ft}$

$k=$ Reservoir permeability, md

$k_{f}=$ Fracture permeability

$L_{H}=$ Lateral well length, $\mathrm{ft}$

$n_{F}=$ Number of fractures

$P_{w D}=$ Dimensionless wellbore pressure

$P_{w f}=$ Wellbore pressure, $\mathrm{psi}$

$m(p)=$ Pseudo pressure, $\mathrm{psi}^{2} / \mathrm{cp}$

$q=$ Well production rate, $\mathrm{stb} / \mathrm{d}$

$q_{g}=$ Well gas production rate, $\mathrm{Mscf} / \mathrm{d}$

$r_{w}=$ Well bore radius, $\mathrm{ft}$

$s_{p}=$ Pseudo skin

$s=$ Skin

$t_{D}=$ Dimensionless time

$t_{D x f}=$ Dimensionless time based on $\mathrm{x}_{\mathrm{f}}$

$t=$ time , hrs

$T=$ Reservoir Temperature, ${ }^{\circ} \mathrm{R}$

$t_{\text {elf }}=$ End of linear flow period, hrs

$t_{s l f}=$ Start of linear flow period, hrs

$\mu=$ Fluid Viscosity, $\mathrm{cp}$

$\emptyset=$ porosity (fraction) 